\title{
Investigation of IR and Raman spectra of species present in formaldehyde-water-methanol systems
}

\author{
Katarzyna Z. Gaca-Zajqc ${ }^{1 *}$, Benjamin R. Smith ${ }^{2}$, Alison Nordon ${ }^{2,3}$, Ashleigh J. Fletcher ${ }^{4}$, Karen \\ Johnston ${ }^{4}$ and Jan Sefcik ${ }^{4 *}$ \\ ${ }^{1}$ Department of Chemistry and Technology of Polymers, Cracow University of Technology, 24 \\ Warszawska Street, 31-155 Cracow, Poland \\ 2 WestChem, Department of Pure and Applied Chemistry, University of Strathclyde, \\ 295 Cathedral Street, Glasgow, G1 1XL, U.K. \\ ${ }^{3}$ Centre for Process Analytics and Control Technology (CPACT), University of Strathclyde, 295 \\ Cathedral Street, Glasgow, G1 1XL, U.K. \\ ${ }^{4}$ Department of Chemical and Process Engineering, University of Strathclyde, 75 Montrose \\ Street, Glasgow, G1 1XJ, U.K. \\ * to whom correspondence should be addressed
}

\begin{abstract}
Formaldehyde forms a variety of hydrated and methoxylated species when reacted with water and methanol. Vibrational spectroscopy has been deployed for both remote and in situ sensing of formaldehyde species and it can be a useful tool for process development, monitoring and control at both laboratory and industrial scale, as well as for environmental, atmospheric and space monitoring. While IR and Raman spectroscopic studies of formaldehyde species in solid, liquid or gas phases have been reported, assignments of vibrational frequencies of relevant species in previous literature have been contradictory and incomplete. In this work we report IR and Raman spectra for formaldehyde-water-methanol solutions across a wide range of formaldehyde concentrations and solvent compositions. We present an analysis of vibrational spectra of formaldehyde-water-methanol systems using a combination of experimental measurements and gas phase quantum mechanical density functional theory simulations. For the first time, we explicitly consider spectra of oligomeric mixtures of formaldehyde species in relation to spectra of specific representative hydrated and methoxylated species and we resolve some previously reported contradictions in assignments of vibrational frequencies for formaldehyde systems.
\end{abstract}

KEYWORDS: Formaldehyde, Methylene glycol, methanediol, methoxylated methylene glycol, methoxymethanol, dimethyleneglycol, di(oxymethylene)glycol, FTIR, Raman, vibrational frequencies, vibrational spectra, spectroscopy 


\section{Introduction}

Formaldehyde solutions are commonly used as reactants and precursors in synthesis of many chemical intermediates [1] and polymeric materials, including resins and nanoporous organic gels [2-5]. Formaldehyde-water-methanol solutions are frequently used in both laboratory and industrial environments where IR and Raman spectroscopies can both be deployed in situ and can be invaluable tools for process development, monitoring and control. Both qualitative and quantitative vibrational spectroscopic analysis of hydrated and methoxylated formaldehyde species is thus required. However, assignments of vibrational frequencies of relevant species have been incomplete and to some extent contradictory in previous literature, while the speciation in formaldehyde-water-methanol systems has been only recently quantitatively investigated [4]. Hydrated and methoxylated formaldehyde-based species are also of interest in many other fields, including environmental, atmospheric and space sciences [2,6-8], where monitoring of these species can only be achieved by vibrational spectroscopy-based sensing and accurate measurement of their concentrations is crucial for assessment and validation of climate models as well as understanding of interplanetary and interstellar chemistry.

Formaldehyde hydration to methylene glycol $\left(\mathrm{MG}, \mathrm{HO}-\mathrm{CH}_{2}-\mathrm{OH}\right)$, also called methanediol, and their subsequent polymerisation to diglycol, or dimethylene glycol (DG, $\mathrm{HO}-\mathrm{CH}_{2}-\mathrm{O}-\mathrm{CH}_{2}-\mathrm{OH}$ ), triglycol (TG, $\left.\mathrm{HO}-\mathrm{CH}_{2}-\mathrm{O}-\mathrm{CH}_{2}-\mathrm{O}-\mathrm{CH}_{2}-\mathrm{OH}\right)$ and so on is favourable in aqueous solution [4]:

$$
\text { (a) } \mathrm{CH}_{2} \mathrm{O}+\mathrm{H}_{2} \mathrm{O} \rightleftharpoons \mathrm{HO}\left(\mathrm{CH}_{2} \mathrm{O}\right) \mathrm{H}
$$

$$
\text { (b) } \mathrm{HO}\left(\mathrm{CH}_{2} \mathrm{O}\right)_{\mathrm{i}-1} \mathrm{H}+\mathrm{HO}\left(\mathrm{CH}_{2}\right) \mathrm{OH} \rightleftharpoons \mathrm{HO}\left(\mathrm{CH}_{2} \mathrm{O}\right)_{\mathrm{i}} \mathrm{H}+\mathrm{H}_{2} \mathrm{O} \quad \mathrm{i} \geq 2
$$

However, when polymerisation is undesirable (such as in highly concentrated formaldehyde solutions available commercially), methanol is added as a stabiliser. In the presence of methanol, formaldehyde forms methoxylated methylene glycol ( $\left.\mathrm{MMG}, \mathrm{CH}_{3} \mathrm{O}-\mathrm{CH}_{2}-\mathrm{OH}\right)$, also called methoxymethanol, and related oligomers, such as methoxy diglycol ( $\mathrm{MDG}, \mathrm{CH}_{3} \mathrm{O}-\mathrm{CH}_{2}-\mathrm{O}-\mathrm{CH}_{2}-$ $\mathrm{OH})$ and methoxy triglycol (MTG, $\left.\mathrm{CH}_{3} \mathrm{O}-\mathrm{CH}_{2}-\mathrm{O}-\mathrm{CH}_{2}-\mathrm{O}-\mathrm{CH}_{2}-\mathrm{OH}\right)$ [4]:

$$
\begin{gathered}
\text { (c) } \mathrm{HO}\left(\mathrm{CH}_{2} \mathrm{O}\right) \mathrm{H}+\mathrm{CH}_{3} \mathrm{OH} \rightleftharpoons \mathrm{HO}\left(\mathrm{CH}_{2} \mathrm{O}\right) \mathrm{CH}_{3}+\mathrm{H}_{2} \mathrm{O} \\
\text { (d) } \mathrm{HO}\left(\mathrm{CH}_{2} \mathrm{O}\right)_{\mathrm{i}-1} \mathrm{H}+\mathrm{CH}_{3} \mathrm{OH} \rightleftharpoons \mathrm{HO}\left(\mathrm{CH}_{2} \mathrm{O}\right)_{\mathrm{i}-1} \mathrm{CH}_{3}+\mathrm{H}_{2} \mathrm{O} \quad \mathrm{i} \geq 2
\end{gathered}
$$

Since methoxylation of methylene glycol and its oligomers is relatively favourable compared to polymerisation, the degree of polymerisation is much lower in the presence of methanol. All these reactions are acid and base catalysed but they proceed relatively rapidly in aqueous methanolic solutions even without adding any catalyst [4]. Further methoxylation of MMG to $\mathrm{CH}_{3} \mathrm{O}\left(\mathrm{CH}_{2} \mathrm{O}\right) \mathrm{CH}_{3}$ is favoured thermodynamically but does not proceed without a sufficient amount of catalyst [9].

Several studies were carried out to investigate the speciation in aqueous formaldehyde solutions in the absence of methanol obtained by depolymerisation of pure formaldehyde polymer (paraformaldehyde or poly(oxymethylene)) using NMR [10,11], while formaldehyde solutions in pure methanol were investigated as well [12]. Despite the widespread use of commercial formaldehyde stock solutions, the quantitative speciation in aqueous formaldehyde solutions containing methanol has only recently been investigated in detail using NMR spectroscopy [4]. 
Raman spectra of formaldehyde solutions were first reported by Matsuura et al. [13]. Although commercial formaldehyde stock solutions stabilised by methanol were used in this study, Matsuura et al. assumed that these solutions contain only methylene glycol, water and methanol when making assignments of vibrational frequencies, as it was not known at that time that these solutions contain a large fraction of oligomers and methoxylated oligomers in addition to methylene glycol. Further studies on aqueous formaldehyde solutions in the absence of methanol $[14,15]$ suggested assignments for observed Raman spectra over a wide range of concentrations where numerous oligoglycol species were present in solutions. Raman spectroscopic studies of frozen aqueous formaldehyde solutions were also reported [8] as well as studies of phenolformaldehyde solutions [16]. However, formaldehyde solutions containing methoxylated species have not been investigated previously using Raman spectroscopy.

IR spectra of MG and MMG in gas phase [6,7,17] as well as MMG in methanol [18] were reported as well as liquid phase IR spectra of formaldehyde aqueous solutions over a relatively narrow spectral range [19]. Studies of phenol-formaldehyde resins using IR spectroscopy were also reported [20]. More recently, vibrational frequencies of MG, MMG and DG were computed using quantum mechanical methods [7,21-23]. Similarly to Raman spectroscopy, formaldehydewater-methanol solutions containing methoxylated species have not been investigated previously using IR spectroscopy.

In this work, we report IR and Raman spectra for commercial formaldehyde stock solutions diluted with either water or methanol across a wide range of formaldehyde concentrations. We present a detailed characterisation of vibrational frequencies observed in formaldehyde-watermethanol systems using a combination of experimental measurements and quantum mechanical density functional theory simulations, while for the first time considering vibrational spectra of complex oligomeric mixtures of formaldehyde species together with those of specific representative species, including $\mathrm{MG}, \mathrm{MMG}$ and $\mathrm{DG}$.

\section{Methods}

\section{Sample preparation}

Table 1 shows the compositions of mixtures investigated in this research. Required amount of formaldehyde stock solution (37\%wt.; Sigma-Aldrich UK) stabilised by 13\%wt. of methanol [24] was measured into a glass beaker equipped with a magnetic bar (14x5 mm, PTFE surface) and placed on a magnetic stirrer. After required amount of diluent was added, either de-ionised water from in-house supply (Millipore Elix 5) or methanol $(\geq 99.8 \%$ wt., ACS grade, VWR International), the beaker was covered with parafilm to prevent evaporation and the contents were stirred for $5 \mathrm{~min}$. The measurements were performed directly afterwards in the same vessel.

\section{Attenuated Total Reflection (ATR) Fourier Transform Infra-Red (FTIR) Spectroscopy}

MB3000 mid-IR Fourier Transform spectrometer manufactured by ABB Inc., equipped with class 3B laser $(760 \mathrm{~nm}, 2 \mathrm{~mW}$ output power) and an ATR probe manufactured by Fibre Photonics linked with the FTIR by an optical polycrystalline silver halide fibre cable, were used. Due to the fact that an ATR diamond probe was used in all IR experiments, the range of wavenumbers accessible was limited by a diamond resonance signal at ca. $2000 \mathrm{~cm}^{-1}$, and limited 
due to poor throughput of light by the optical fibre cable above $2000 \mathrm{~cm}^{-1}$, therefore the spectra between $800 \mathrm{~cm}^{-1}$ and $1700 \mathrm{~cm}^{-1}$ were collected and analysed. The ATR probe was immersed in the solution, while gently agitating the contents to minimize the effect of local concentration differences. All experiments were carried out at room temperature with the same set of parameters: 16 scans, resolution $8 \mathrm{~cm}^{-1}$, using de-ionised water as a background. Background subtraction, baseline correction and peak deconvolution for measured IR spectra was done using Origin software.

\section{Raman Spectroscopy}

All spectra were collected using a Leica DM/LM microscope equipped with an Olympus 20x/0.4 long working distance objective, which was used to collect $180^{\circ}$ backscattered light from macrosampler. The spectrometer system was a Renishaw inVia equipped with a helium-neon $(\mathrm{He}-\mathrm{Ne} ; \lambda=632.8 \mathrm{~nm}$ ) laser coupled with Renishaw Ramascope System 2000. Background subtraction, baseline correction and peak deconvolution for measured Raman spectra was done using Origin software.

\section{Simulation of Vibrational Frequencies}

Simulated vibrational frequencies were calculated using the Quantum ESPRESSO package, version 5.1 [25], which implements density functional theory (DFT) using a plane wave basis set. Molecules were generated with the aid of the chemical drawing tool Avogadro (http://avogadro.cc/). Projector augmented wave pseudopotentials, C.pbe-n-kjpaw_psl.0.1.UPF, O.pbe-n-kjpaw_psl.0.1.UPF and H.pbe-kjpaw_psl.0.1.UPF, were taken from the Quantum ESPRESSO pseudopotential data base: http://www.quantum-espresso.org/pseudopotentials. The PBE version [26] of the generalised gradient approximation was used for the exchange and correlation functional. Cut-offs of 50 Ry and 200 Ry were used for the wavefunctions and charge densities, respectively. The molecules were ionically relaxed in a cubic cell of side $20 \mathrm{Bohr}$, using a single k-point, an electronic convergence threshold of $1 \times 10^{-10} \mathrm{Ry}$, and a force convergence threshold of $1 \times 10^{-3}$ a.u. The vibration frequencies and IR intensities were calculated using the PHonon package, which implements density functional perturbation theory, and a selfconsistency threshold of $1 \times 10^{-18}$ Ry was used. The vibrational mode characters were assigned by viewing individual vibrational modes in Molden [27].

\section{Results and Discussion}

\section{IR and Raman spectra: qualitative analysis}

IR and Raman spectroscopy provide information about the vibrational spectra of species present in given solution matrices. These two techniques are complementary, as certain functional groups in molecules might be invisible in IR due to the fact they have no dipole moment but may be observed in Raman spectra due to their polarizability. Figure 1 shows comparison of IR and Raman spectra for the stock formaldehyde solution (37\%wt. formaldehyde and $13 \%$ wt. methanol in water), where one can see a number of vibrational frequencies in the region of wavenumbers between 800 and $1700 \mathrm{~cm}^{-1}$. A very similar Raman spectrum was reported previously by Matsuura et al., see their Figure 1 [13], although the authors assumed that all signals come from either MG or methanol. However, this is not the case as numerous methylene glycol oligomers and methoxylated oligomers are present in these highly concentrated solutions [4]. A comparable 
IR spectrum of a stock formaldehyde solution was reported previously by Poljansek and Krajnc, see their Figure 1 [20].

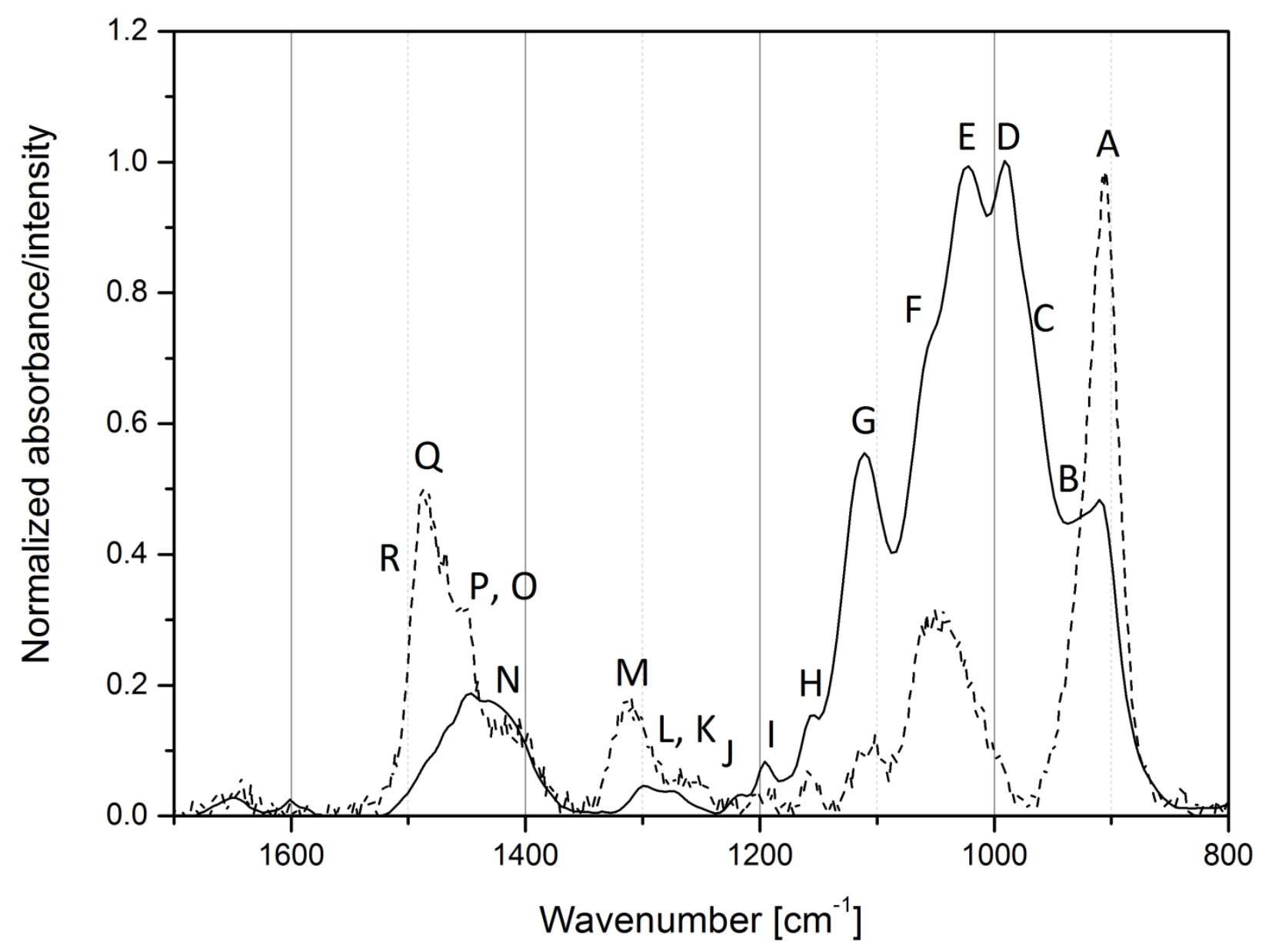

Figure 1. Normalised IR (solid line) and Raman (dashed line) spectra of the stock formaldehyde solution. Peaks A-R, assigned in Table 5 based on experimental spectra and vibrational frequency calculations, are indicated, although some are not apparent in these particular spectra.

In Figures 2 and 3 we show IR and Raman spectra measured for progressively diluted formaldehyde stock solutions, using either water or methanol as diluents.

As stock formaldehyde solutions are progressively diluted with either water or methanol, the distribution of formaldehyde related species changes. Since oligomerisation of methylene glycol is a second order reversible reaction, dilution with solvent results in reverse oligomerisation. In dilution with water, methanol present in the original stock solution is diluted as well, and since methoxylation is also second order reversible reaction, dilution with water results in reverse methoxylation. 
a

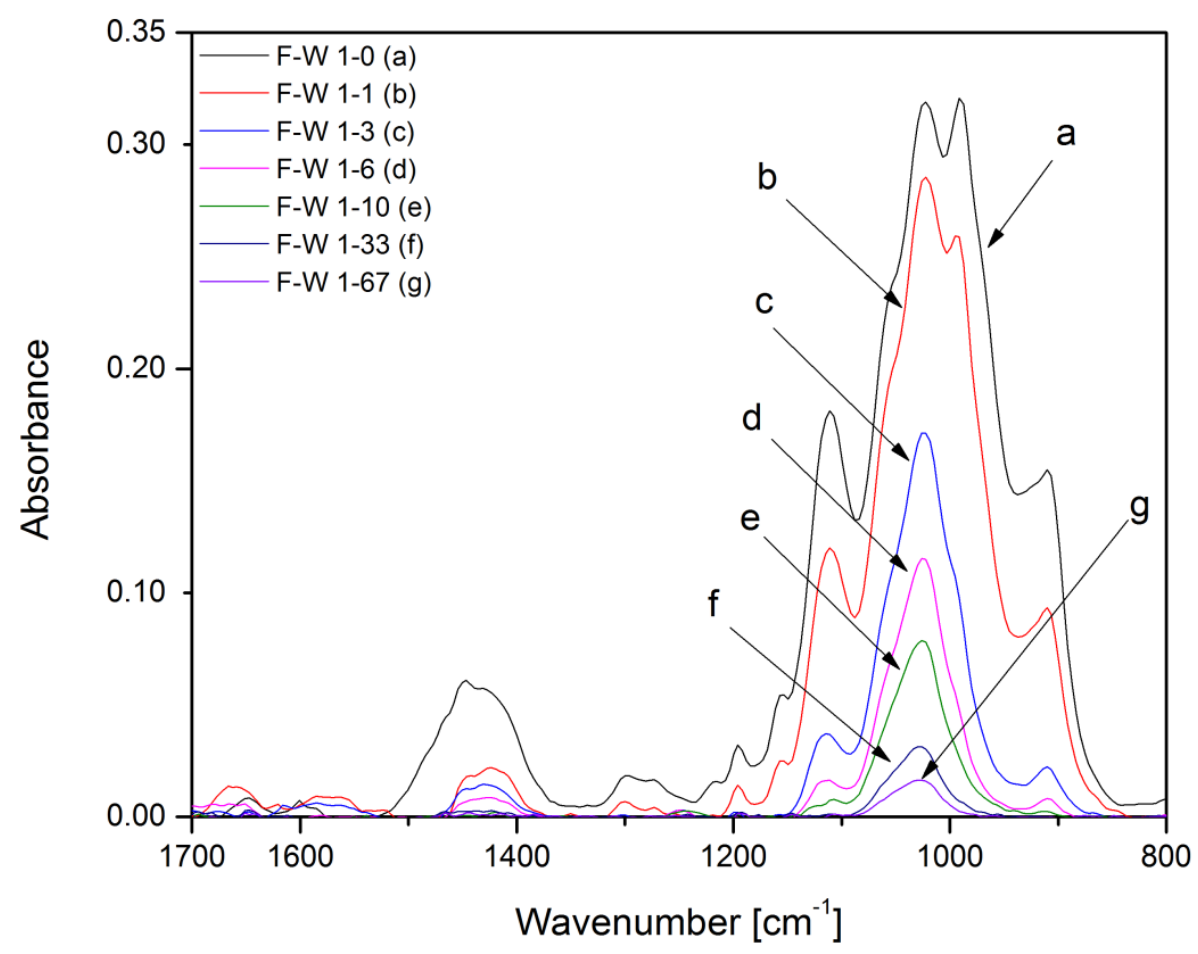

b

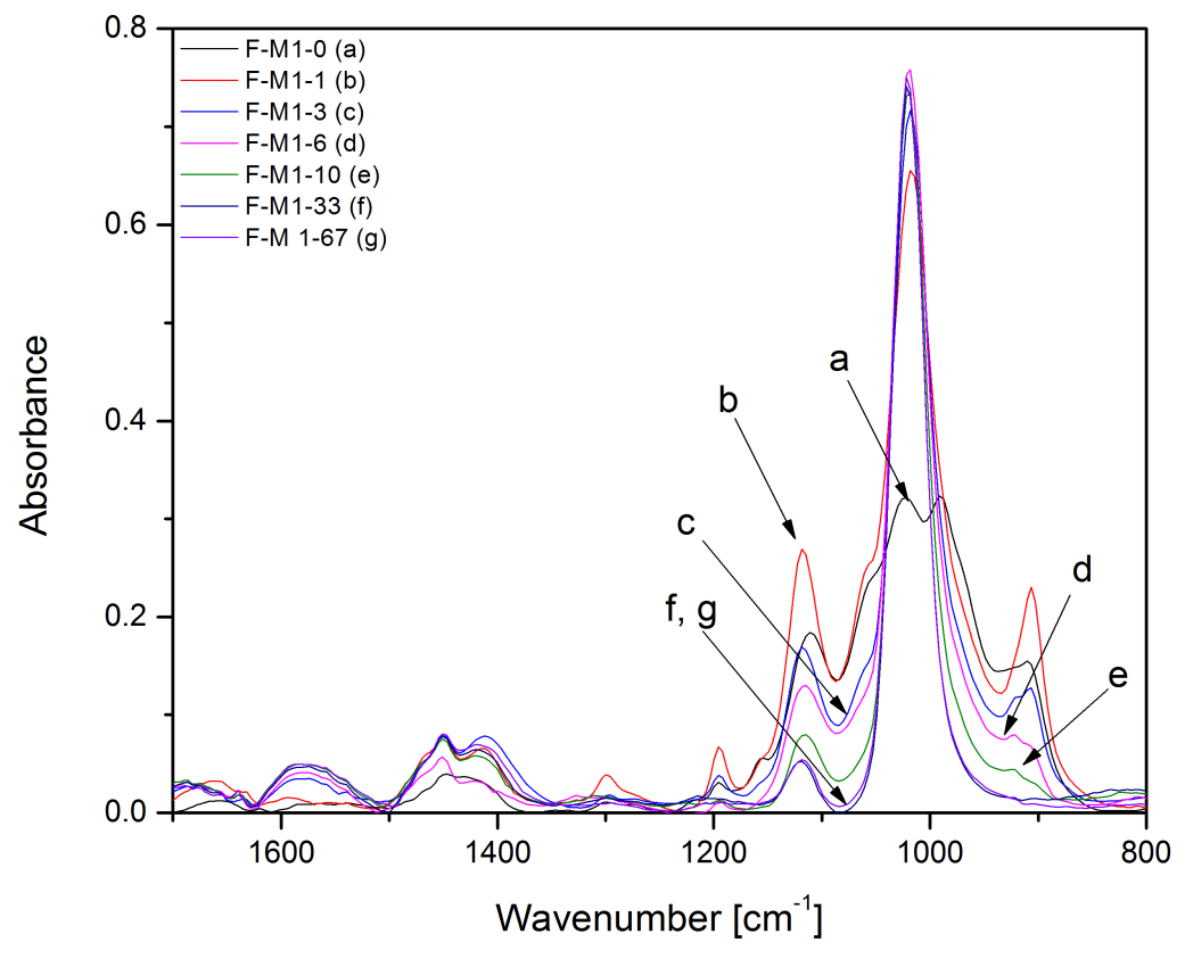

Figure 2. IR spectra of formaldehyde stock solutions diluted with water (a) or with methanol (b). See Table 1 for corresponding solution compositions. 


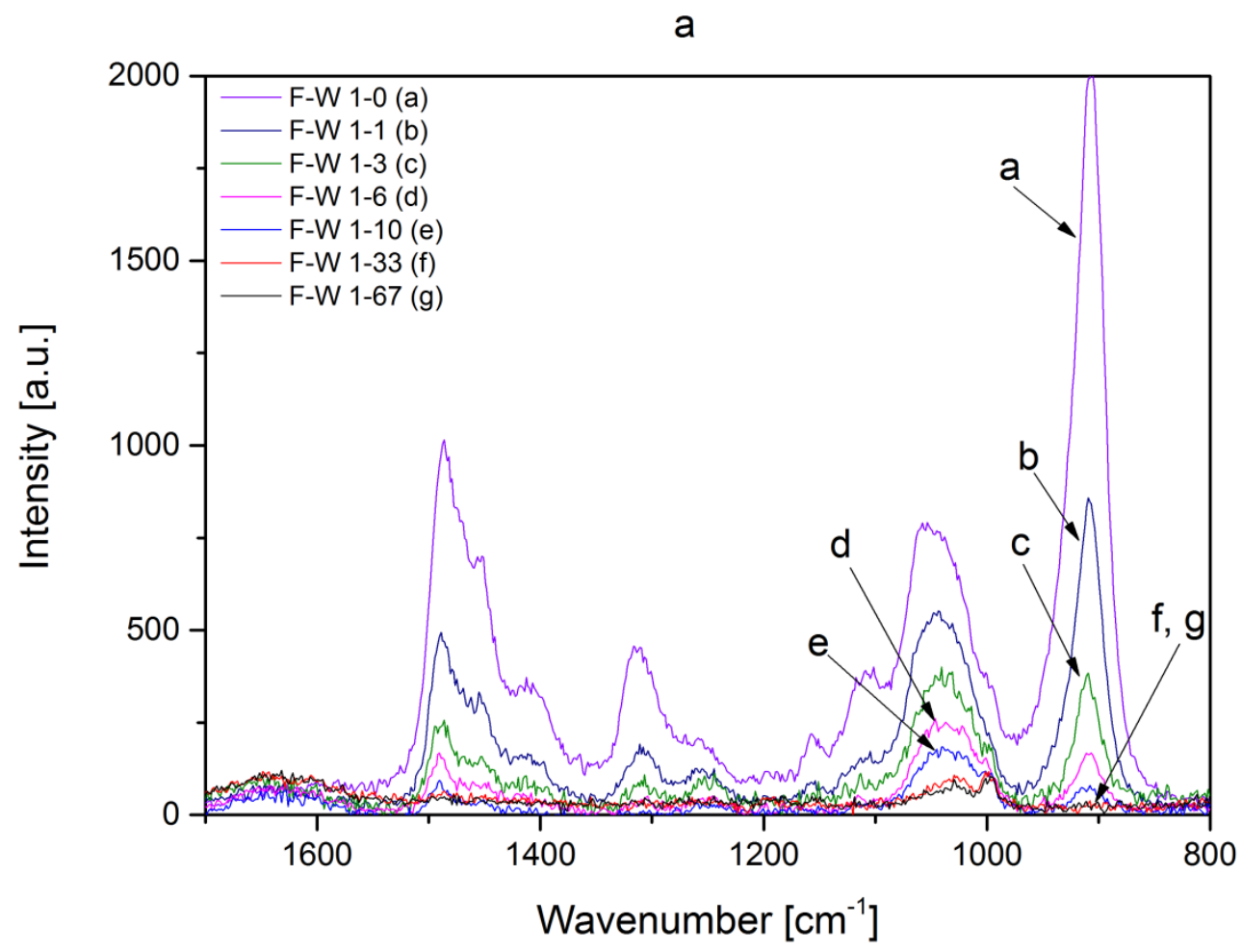

b

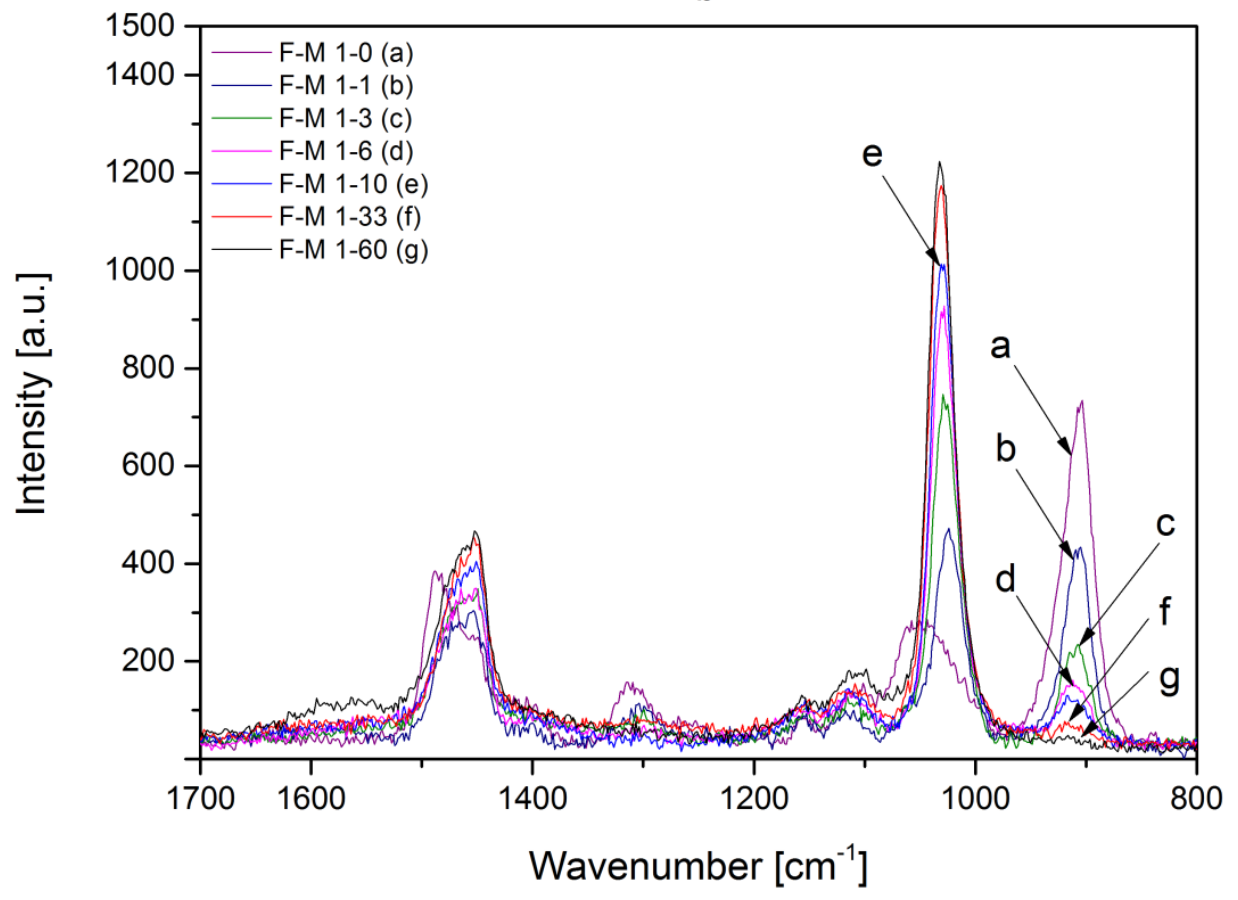


Figure 3. Raman spectra of formaldehyde stock solutions diluted with water (a) or with methanol (b). See Table 1 for corresponding solution compositions.

Therefore in the limit of large dilutions, monomeric methylene glycol is present as the major formaldehyde containing species, accompanied by minor amounts of MMG and methanol [4], in formaldehyde stock solutions diluted with water. In the case of dilution of stock formaldehyde solutions with methanol, methoxylation is favoured and in the limit of large dilutions methoxylated methylene glycol is present as the major formaldehyde containing species, accompanied by minor amounts of MDG and even less of MG [4], while spectra become dominated by methanol itself (see vibrational spectra of methanol and methanol-water mixtures in Figures S7 and S8 in Supporting Information). Consequently, formaldehyde-related contribution to spectra changes due to decreasing absolute concentration of formaldehyde containing species as well as changing speciation, while methanol-related contribution to spectra increases upon methanol addition. Significantly, peaks at $910 \mathrm{~cm}^{-1}, 1110 \mathrm{~cm}^{-1}, 1195 \mathrm{~cm}^{-1}$ and $1300 \mathrm{~cm}^{-1}$ initially increase in the IR spectra upon dilution with methanol (see Figure $2 \mathrm{~b}$ ) and then gradually decrease. However, all of these peaks gradually decrease and then vanish in the IR spectra upon dilution with water (see Figure 2a). This indicates that the corresponding vibrational frequencies are present in methoxylated species (such as MMG and MDG) which are thermodynamically favoured in the presence of methanol. On the other hand, peak at $1025 \mathrm{~cm}^{-1}$ decreases in both IR and Raman spectra upon dilution with water but persists until the highest dilution, indicating that that the corresponding vibrational frequency is present in monomeric methylene glycol. At the same time, it can be seen that the same peak increases in both IR and Raman spectra upon dilution with methanol, so it is clearly also related to a vibrational frequency present in methanol.

As numerous peaks observed in IR and Raman spectra above may not be uniquely linked to single specific formaldehyde-related species, it is crucial to investigate assignments of vibrational frequencies for most relevant species present in these systems in order to interpret these spectra properly. We will aid this investigation by careful examination of simulated vibrational frequencies and their corresponding vibrational modes using density functional calculations as described in the following section.

\section{Simulated vibrational frequencies}

To gain further insight into the experimental vibrational spectra, we simulated vibrational frequencies for methylene glycol (MG), methoxylated methylene glycol (MMG) and diglycol (DG) using DFT. Formaldehyde and methanol were also calculated for validation purposes and results for these are shown in the Supporting Information. We note that our calculated vibrational spectra correspond to gas phase molecules.

\section{Methylene glycol (MG)}

Methylene glycol has 15 vibrational frequencies. We calculated vibrational frequencies for the lowest energy conformer, corresponding to methanediol-C2 in Barrientos et al. [21]. The vibrational frequencies, intensities and mode assignments are presented in Table 2, with all frequencies listed in ascending order. Vibrational frequencies calculated using second order 
Møller-Plesset perturbation theory (MP2) [21], quadratic configuration interaction including single and double substitutions (QCISD) [21] and DFT polarisable continuum model (PCM) [22] are also shown in ascending order in Table 2. Our data is in excellent agreement with the QCISD and DFT PCM data and the correlation between our results and the vibrational frequencies in the literature over the range $800-1700 \mathrm{~cm}^{-1}$ is shown in Supporting Information. We note that Barrientos et al. [21] and Delcroix et al. [22] used scaling factors of 0.9624 and 0.989 for the QCISD data and DFT PCM implicit solvent model data, respectively, whereas our results have not been scaled. The relative magnitudes of the QCISD and present DFT IR intensities agree well and both agree that the strongest mode is the OCO stretch mode at our calculated frequency of $1003 \mathrm{~cm}^{-1}$. For the two lowest frequency torsion modes, QCISD predicts that the lowest mode is more intense whereas DFT predicts that the second lowest is more intense. Our assignments mostly agree with the QCISD assignments and the six assignments given by DFT PCM results. The assignments where the agreement is not clear are the 1345 and $1387 \mathrm{~cm}^{-1}$, where our calculations show both $\mathrm{CH}_{2}$ and $\mathrm{OH}$ modes and Barrientos et al. found only $\mathrm{CH}_{2}$ modes. The MP2 data mostly agree with QCISD except that the MP2 assignments for the $1374 \mathrm{~cm}^{-1}$ and $1441 \mathrm{~cm}^{-1}$ modes are $\mathrm{CH}_{2}$ scissor and $\mathrm{CH}_{2}$ wag, which are reversed with respect to QCISD.

We have also shown a comparison with the IR spectroscopic study by Lugez et al. [6]. Their data are also in good agreement with the calculated frequencies, although only 8 frequencies were reported by Lugez et al. Their tentative assignments of the 1354-1359, and 1424-1426 $\mathrm{cm}^{-1}$ modes are $\mathrm{COH}$ in-plane bends only, in contrast with the MP2 and QCISD calculations that predicted $\mathrm{CH}_{2}$ wag or scissor modes. We note again that our data shows both $\mathrm{COH}$ bending and $\mathrm{CH}_{2}$ character for our modes closest to their frequencies.

\section{Methoxylated methylene glycol (MMG)}

Three conformers for MMG were relaxed and their structures are shown in Figure 4. Conformer $\mathrm{A}$ is the lowest energy conformer, and conformers $\mathrm{B}$ and $\mathrm{C}$ are 6.7 and $9.8 \mathrm{~kJ} / \mathrm{mol}$ higher in energy, respectively. The relative ground state energies of the three conformers are in good agreement with the DFT B3LYP study by Wrobel et al. [7] who predicted that conformers B and $\mathrm{C}$ are 8.8 and $9.2 \mathrm{~kJ} / \mathrm{mol}(2.1$ and $2.2 \mathrm{kcal} / \mathrm{mol})$ higher in energy.

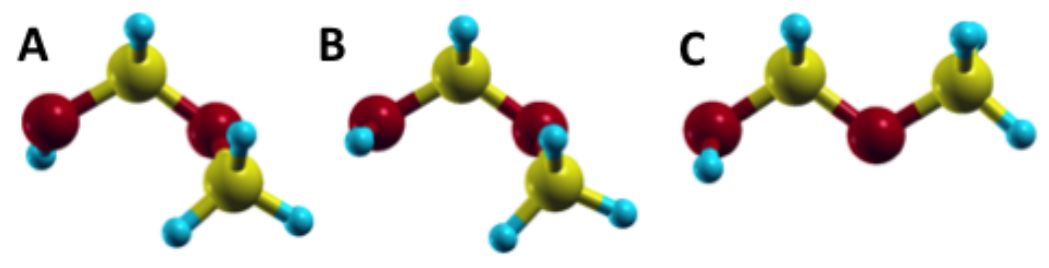

Figure 4. Three conformers of methoxylated methylene glycol (MMG).

MMG has 24 vibrational modes and Table 3 shows the vibrational frequencies in ascending order for the lowest energy conformer alongside previous DFT and experimental data. Vibrational frequencies for conformer B are similar to those for conformer A, and are given in the Supporting Information. There is reasonable agreement between our DFT PBE frequencies and the B3LYP 
frequencies of Wrobel et al, although the deviation increases at higher frequencies, as shown in the correlation plot in Supporting Information. Wrobel et al also measured the IR spectra for MMG in argon matrix isolation experiments at $10 \mathrm{~K}$ and these results also agree well with the DFT calculations. Vibrational frequencies for the second lowest energy conformer are shown in Table S3 in Supporting Information and the frequencies are similar to those of conformer A. We also compared the frequencies with a gas phase FT-IR study by Johnson and Stanley [17]. These results were mostly in agreement, except for the $1052 \mathrm{~cm}^{-1}$ mode. All other studies found a single peak/frequency near $1050 \mathrm{~cm}^{-1}$ but Johnson and Stanley suggested there were two peaks in the measured spectra, at 1046 and $1052 \mathrm{~cm}^{-1}$. However, we believe that there is likely to be only a single peak and that the appearance of the double peak is due to noise in their measured spectra. We also compared our results with an IR spectroscopy study of MMG formed by irradiation of liquid methanol [18]. They only reported 5 frequencies and did not report assignments so we have presented the frequencies in Table 3 beside the nearest frequencies. Our assignments for conformer A are also presented in Table 3. The agreement with the assignments of Wrobel et al. is mixed. In general, there is good agreement regarding the involved groups but often the mode types, e.g., bend vs scissor do not agree. However, we note that some of the modes for MMG are not easy to define and appear to be a mix of different modes. The files containing the mode frequencies and modes are available as electronic Supporting Information.

\section{Diglycol (DG)}

For DG, we considered four conformations of the molecule, labelled A, B, C and D, as shown in Figure 5. Conformer A has the lowest energy, followed by B, C and D, which are $3.4 \mathrm{~kJ} / \mathrm{mol}$, $10.9 \mathrm{~kJ} / \mathrm{mol}$ and $28.5 \mathrm{~kJ} / \mathrm{mol}$ higher in energy, respectively. Structures similar to conformers A and B were calculated by Delcroix et al. [23] and they found that conformer $\mathrm{A}$ is $1.3 \mathrm{~kJ} / \mathrm{mol}$ lower in energy. However, they discarded this conformer as they expected that the H-bond between the $\mathrm{OH}$ groups would not be predominant in solution.

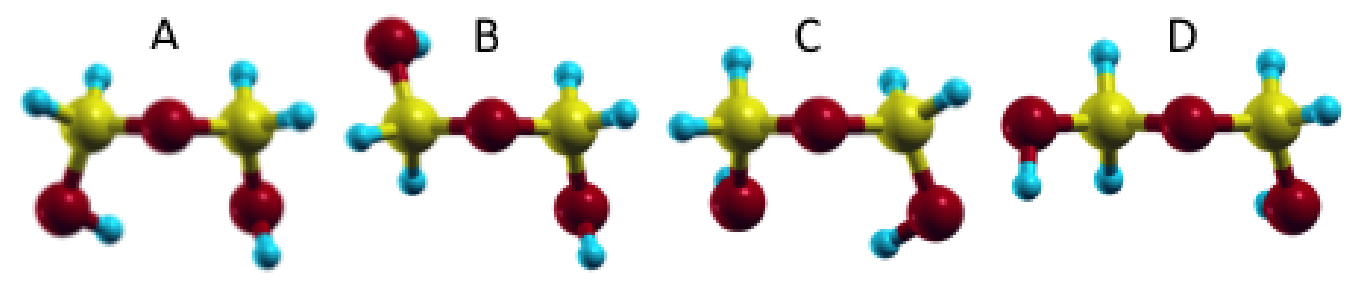

Figure 5. Four conformers of diglycol (DG).

DG has 27 vibrational frequencies and these are shown in Table 4 in ascending order for conformers $\mathrm{A}$ and $\mathrm{B}$. The frequencies for conformers $\mathrm{A}$ and $\mathrm{B}$ differ by less than $50 \mathrm{~cm}^{-1}$ over our experimental range of $800-1700 \mathrm{~cm}^{-1}$. The study by Delcroix et al. calculated vibrational frequencies for the isolated DG molecule and also for the solvated molecule in implicit and explicit water [23]. Here we have reported their data for the isolated molecule only as they reported more than 27 vibrational frequencies for DG with explicit water. For the anharmonic isolated case they reported only 26 frequencies and for the harmonic isolated case they reported all 27 frequencies and used a scaling factor of 0.989 [23] (also see Supporting Information). Their results are shown alongside the present results in Table 4 and the correlation plot is shown in the Supporting Information. In our experimental range (800-1700 $\left.\mathrm{cm}^{-1}\right)$, our predicted frequencies 
are systematically lower in frequency than both sets of data by Delcroix et al. The assignments of conformers $\mathrm{A}$ and $\mathrm{B}$ are similar. The $3^{\text {rd }}$ and $4^{\text {th }}$ lowest mode assignments are in a different order and a few other modes with mixed assignments differ slightly. Conformer B agrees quite well with Delcroix's assignments for conformer B, with a few differences for the modes with mixed assignments. Delcroix also studied DG in water and found that a few frequencies were significantly different in gas and solvated phases. The only frequency affected that lies within our experimental range is their $1478 \mathrm{~cm}^{-1}$ mode (corresponding to our frequency at $1442 \mathrm{~cm}^{-1}$ ) that shifts to $1520 \mathrm{~cm}^{-1}$.

\section{Assignments of vibrational frequencies}

In order to ascertain assignments of the peaks observed in IR and Raman spectra measured in formaldehyde-water-methanol solutions (see Figures 1-3), we analysed vibrational spectra of representative species ( $\mathrm{MG}, \mathrm{MMG}, \mathrm{DG})$ based on their simulated and previously measured vibrational frequencies (see Tables 2-4). In Table 5 we show assignments of peaks based on our analysis using DFT PBE as well as trends observed in spectra from dilution experiments (see Figures 2 and 3). We also show comparison with previous experimental data for Raman [14,15] and IR [19] spectra of formaldehyde-water solutions, the formaldehyde stock solution containing methanol [13] as well as MG [6] and MMG [7,17,18] species. We note that there are no experimental measurements of DG or any other related species on their own in a solvent or gas.

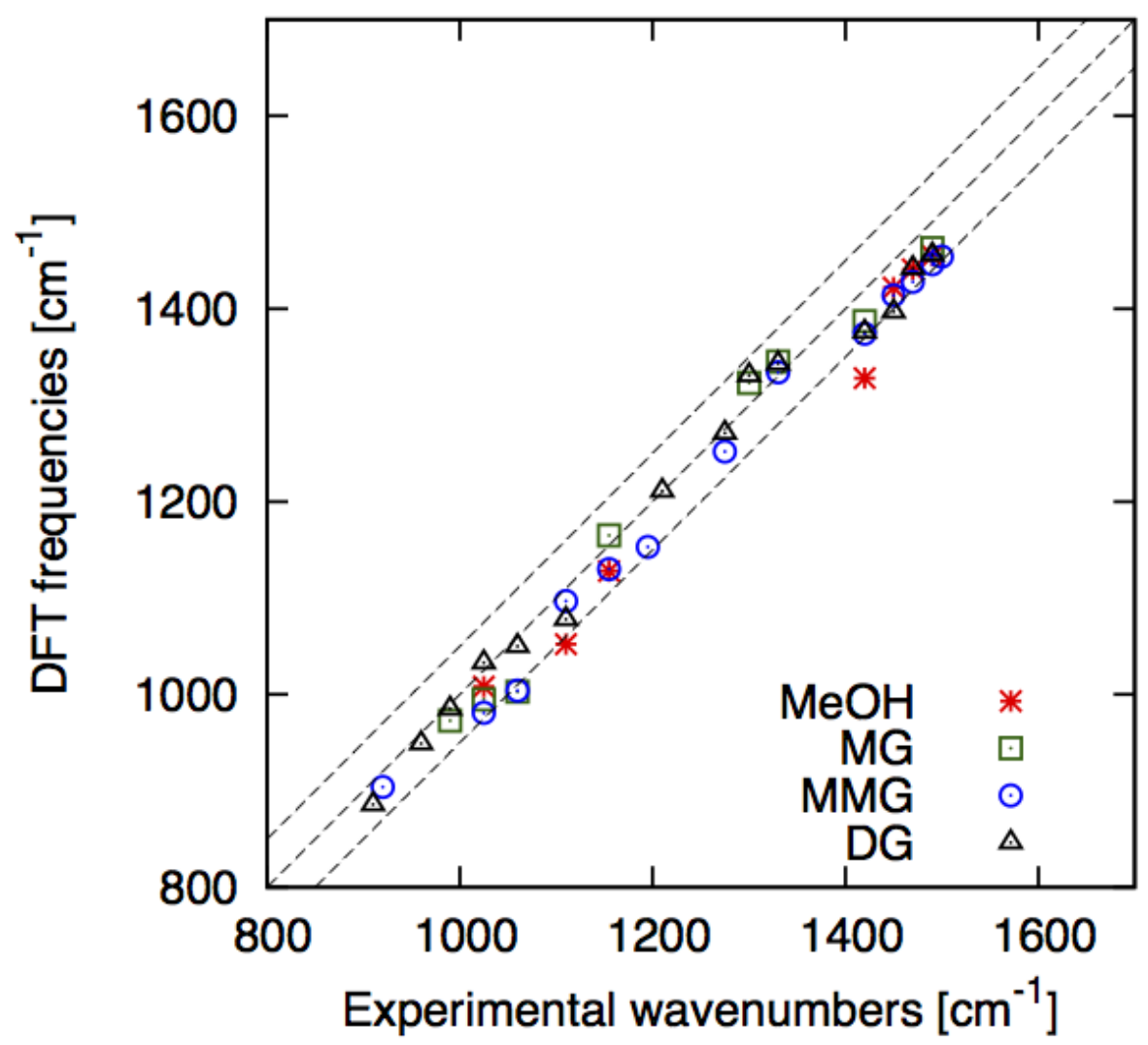

Figure 6. Correlation between calculated DFT frequencies and experimental peak wavenumbers based on assignments in Table 5. Discrepancies for methanol are discussed in the text. 
Figure 6 shows a correlation between calculated DFT frequencies and experimental peak wavenumbers based on assignments in Table 5. The correlation shows that most significant differences between calculated vibrational frequencies (which were obtained in the absence of solvent) and experimental vibrational frequencies for spectra measured in solutions pertain to those cases where there are known to be large solvent effects. Most notably for methanol, while some frequencies remain mostly unchanged between gas and liquid phase spectra, it has been reported [28] that gas phase modes at $1060 \mathrm{~cm}^{-1}$ and $1345 \mathrm{~cm}^{-1}$ shift to $1115 \mathrm{~cm}^{-1}$ and $1418 \mathrm{~cm}^{-1}$ respectively, in the liquid state (see Table S2 in Supporting Information). Similarly, the only frequency within our experimental range where DG vibrational frequencies calculated by Wrobel et al. significantly shifted when going from gas to aqueous solutions is our frequency at $1442 \mathrm{~cm}^{-}$ ${ }^{1}$ that shifts from $1478 \mathrm{~cm}^{-1}$ to $1520 \mathrm{~cm}^{-1}$ [7].

The early work of Matsuura et al. reported Raman spectra of commercial formaldehyde solutions (37\%wt. formaldehyde, 10-15\%wt. methanol). When we compare Raman spectra shown in Figure 1 here with the spectra in Figure 1 in Matsuura et al., we find that both spectra are very similar. While analysing their spectra Matsuura et al. assumed that only $\mathrm{MG}$ and $\mathrm{MeOH}$ were present and results of their computational analysis were interpreted based on this assumption, ignoring oligomeric and methoxylated species present in these solutions, as there was only limited knowledge of formaldehyde speciation at that time. This work was later followed up by Mohlmann and Lebrun et al., where Raman spectra of aqueous formaldehyde solutions were collected and speciation information was taken into account from then available literature [10]. Since only relatively concentrated solutions were considered, resolution of respective species was not possible, although some assignments specific for oligomeric species were suggested (see Table 5). We can see from Table 5 that some frequencies that we assigned to MG or DG were reported by neither Mohlmann nor Lebrun et al., (e.g., peaks D, J, P) and some of their assignments are in disagreement with each other (e.g., peaks K, L/M, N). However, based on our analysis, these peaks correspond to combinations of $\mathrm{CH}_{2}$ twists (peaks $\mathrm{K}, \mathrm{L}$ ) or wags (peak N) and $\mathrm{COH}$ bends in DG. Importantly, many peaks have contributions from multiple species, even in the absence of methanol: while peaks A, C, G, J, K, O, P correspond to DG (and likely to other oligomers as well), peaks D, E, F, L, M, N, Q correspond to both MG and DG. In the presence of methanol, this becomes even more complex, as peaks B, E, F, G, H, I, K, M, N, O, P, Q, R have contributions from MMG and peaks $\mathrm{E}, \mathrm{G}, \mathrm{H}, \mathrm{N}, \mathrm{O}, \mathrm{P}, \mathrm{Q}$ have contributions from methanol.

Ryabova et al. and to some extent also Lebrun et al. based their assignments on quantitative correlations between areas of deconvoluted peaks and concentrations of specific species in aqueous formaldehyde solutions. While Lebrun et al. have only identified peaks likely to correspond to oligomers (in agreement with our assignments), Ryabova et al. also assigned specific peaks to MG, DG and TG (1050, 1072 and $1100 \mathrm{~cm}^{-1}$, respectively, in their IR spectra), in addition to assigning frequencies 992 and $1026 \mathrm{~cm}^{-1} \mathrm{C}-\mathrm{O}-\mathrm{C}$ stretch in oligomers. While we agree with the last two assignments (our peaks $\mathrm{D}$ and $\mathrm{E}$ ), we note that both these peaks have a contribution from MG as well, and their MG assignment (our peak F) has a contribution from DG as well. Their TG assignment (our peak G) has a contribution from DG and finally their DG assignment at $1072 \mathrm{~cm}^{-1}$ appears very small in the deconvolution plot shown in their Figure 1 and may be an artefact. On the other hand, it was observed by Lebrun et al. that the peak in Raman spectra around $1059 \mathrm{~cm}^{-1}$ (corresponding to our peak F) shifts to about $1070 \mathrm{~cm}^{-1}$ as concentration of formaldehyde increases, indicating that there may be two peaks near each other, 
each of them possibly corresponding to contributions with varying proportions from similar species.

Overall, we can see that similar vibrational frequencies can be expected for multiple formaldehyde species and there are only very few peaks that may be uniquely assigned to specific groups of species. In aqueous formaldehyde systems (in the absence of methanol) these are: peak $\mathrm{H}$ for the hydrated monomer (MG) and peaks $\mathrm{A}, \mathrm{C}, \mathrm{G}, \mathrm{J}, \mathrm{K}, \mathrm{O}, \mathrm{P}$ for oligomers (DG and higher). In the presence of methanol, there are only few peaks, B, I and R, specific to just MMG within the spectral range investigated, with others overlapping with MG, DG or methanol. However, since there are numerous vibrational modes that are close to each other, the corresponding peaks in measured spectra would overlap to various degrees and therefore there may be additional peaks that have yet to be identified, e.g., see shoulder around $1380 \mathrm{~cm}^{-1}$. Furthermore, there are further minor species present in moderately diluted formaldehyde-water-methanol solutions, such as MDG [4], which have not been specifically considered here; for example, there could be contribution from MDG vibrational modes to peaks A (assigned to DG) or B (assigned to MMG).

We have also attempted to correlate concentrations of formaldehyde-based species obtained previously using NMR [4] with intensities of deconvoluted peaks from IR and Raman spectra obtained from formaldehyde-water-methanol solutions [24]. However, the main challenge has been that the solution matrix composition influences both IR and Raman spectra in terms of the areas under the peaks, as well as vibrational frequencies [29], some of which are sensitive to changes in the water-methanol ratio in the solvent matrix. This can be seen clearly in IR and Raman spectra of pure methanol when compared with those of methanol-water mixtures (see Figures S7 and S8 in Supporting Information).

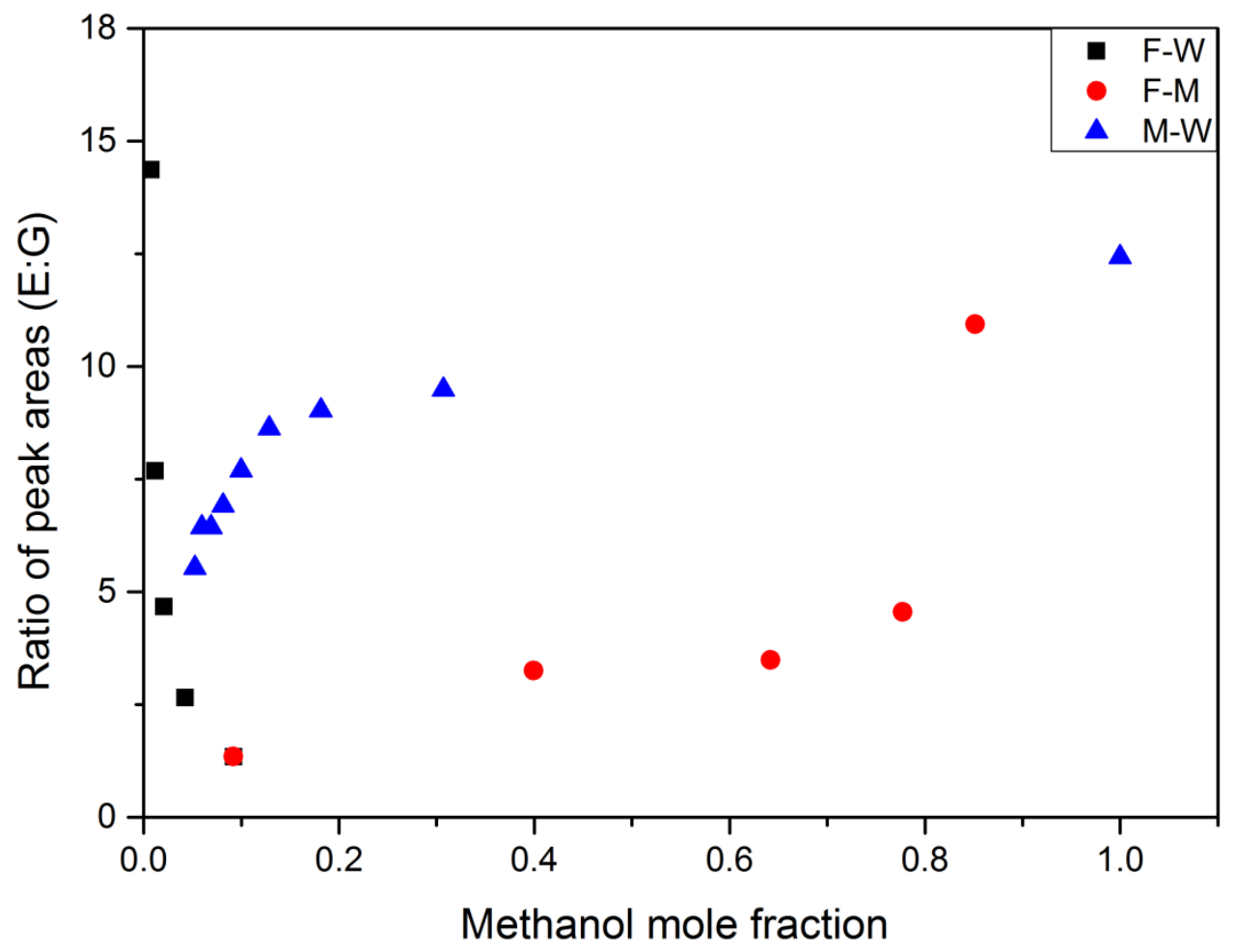


Figure 7. Ratio of areas of deconvoluted peaks E and G from IR spectra of formaldehyde stock solutions diluted with water $(\mathrm{F}-\mathrm{W})$, formaldehyde stock solutions diluted with methanol (F-M) and methanol-water mixtures $(\mathrm{M}-\mathrm{W})$.

Figure 7 shows the ratio of areas of deconvoluted peaks E and G observed in IR spectra at 1025 and $1110 \mathrm{~cm}^{-1}$ collected for formaldehyde-water-methanol solutions, as well as those for methanol-water mixtures. For formaldehyde stock solutions, the ratio of the peak areas increases with increasing dilution with water (as the methanol mole fraction in the solution decreases) and it also increases with increasing dilution with methanol (as the methanol mole fraction in the solution increases).In the case of dilution with water this is expected, as peak $\mathrm{E}$ has a contribution from $M G$, DG, MMG and methanol, while peak $G$ has contribution from DG, MMG, and methanol but not from MG, and upon dilution speciation distribution shifts toward MG. On the other hand, the trend observed for methanol-water mixtures shows that the peaks corresponding to methanol change their relative areas as the solvent matrix changes, so in the case of dilution with methanol the spectrum is gradually approaching that of methanol. Therefore it is not possible to quantify concentrations of individual species bases on simple univariate assumptions about relationships between peak areas and individual species concentrations, especially when the solvent matrix is changing. Furthermore, concentrations of various species which are in mutual equilibria would be strongly correlated, so for example concentrations of MG and MMG would be approximately proportional to each other at a given methanol to water ratio. Therefore more sophisticated multivariate models taking into account the solvent matrix would be required for quantitative interpretation of vibrational spectra of formaldehyde-water-methanol systems.

\section{Conclusions}

We have reported IR and Raman spectra for formaldehyde-water-methanol solutions across a wide range of formaldehyde concentrations (mole fractions from 0.004 to 0.279 ) and solvent compositions (methanol mole fractions form 0.001 to 0.974 ). Solutions were prepared by diluting commercial formaldehyde stock solutions $(37 \% \mathrm{wt}$ formaldehyde, $13 \%$ wt methanol) with either water or methanol. Resulting solutions contained a wide range of hydrated and methoxylated formaldehyde species, from just methylene glycol (MG) and methoxylated methylene glycol (MMG) at the highest dilution with water and methanol, respectively, to a complex mixture of their oligomers at the highest formaldehyde concentration. We have present a detailed characterisation of vibrational frequencies of formaldehyde-water-methanol systems using a combination of experimental measurements and quantum mechanical density functional theory simulations, while for the first time considering vibrational spectra of oligomeric mixtures of formaldehyde species together with those of specific representative species, including $\mathrm{MG}, \mathrm{MMG}$ and diglycol (DG). 


\section{Tables}

Table 1. Compositions of formaldehyde solutions diluted with water (F-W) or with methanol (F-M). F-W 1-0 and F-M 1-0 correspond to the original formaldehyde stock solution.

\begin{tabular}{|c|c|c|c|c|c|c|}
\hline \multirow{2}{*}{ Sample } & Formaldehyde & \multicolumn{2}{|c|}{ Added diluent [ml] } & \multicolumn{3}{c|}{ Mole fractions } \\
\cline { 3 - 7 } & stock solution [ml] & Water & Methanol & Water & Methanol & Formaldehyde \\
\hline F-W 1-0 & 3.00 & 0 & 0 & 0.629 & 0.092 & 0.279 \\
\hline F-W 1-1 & 2.00 & 2.00 & 0 & 0.828 & 0.043 & 0.130 \\
\hline F-W 1-3 & 1.00 & 3.00 & 0 & 0.917 & 0.021 & 0.063 \\
\hline F-W 1-6 & 1.00 & 6.00 & 0 & 0.953 & 0.012 & 0.035 \\
\hline F-W 1-10 & 1.00 & 10.0 & 0 & 0.970 & 0.007 & 0.022 \\
\hline F-W 1-33 & 1.00 & 33.0 & 0 & 0.991 & 0.002 & 0.007 \\
\hline F-W 1-67 & 1.00 & 67.0 & 0 & 0.995 & 0.001 & 0.004 \\
\hline F-M 1-0 & 3.00 & 0 & 0 & 0.629 & 0.092 & 0.279 \\
\hline F-M 1-1 & 2.00 & 0 & 2.00 & 0.416 & 0.399 & 0.185 \\
\hline F-M 1-3 & 1.00 & 0 & 3.00 & 0.248 & 0.642 & 0.110 \\
\hline F-M 1-6 & 1.00 & 0 & 6.00 & 0.155 & 0.777 & 0.069 \\
\hline F-M 1-10 & 1.00 & 0 & 10.0 & 0.103 & 0.852 & 0.046 \\
\hline F-M 1-33 & 1.00 & 0 & 33.0 & 0.035 & 0.949 & 0.016 \\
\hline F-M 1-67 & 0.50 & 0 & 33.5 & 0.018 & 0.974 & 0.008 \\
\hline
\end{tabular}


Table 2. Vibrational frequencies $\left[\mathrm{cm}^{-1}\right]$, infrared intensities and assignments for methylene glycol (MG). Vibrational modes: torsion $(\mathrm{t})$, stretch $(v)$, symmetric stretch $\left(v_{\mathrm{s}}\right)$, antisymmetric stretch $\left(v_{\mathrm{a}}\right)$, bend $(\delta)$, twist $(\tau)$, scissor $(\sigma)$, wag $(\omega), \operatorname{rock}(\rho)$.

\begin{tabular}{|c|c|c|c|c|c|c|c|c|c|c|c|}
\hline \multicolumn{5}{|c|}{ Vibrational Frequencies } & \multicolumn{2}{|c|}{ IR intensity } & \multicolumn{5}{|c|}{ Assignment } \\
\hline $\begin{array}{l}\text { DFT } \\
\text { PBE }\end{array}$ & MP2 & QCISD & $\begin{array}{l}\text { DFT } \\
\text { PCM }\end{array}$ & Expt & DFT PBE & QCISD & DFT PBE & MP2 & QCISD & $\begin{array}{l}\text { DFT } \\
\text { PCM }\end{array}$ & Expt \\
\hline Present & $\begin{array}{r}\text { Barrie } \\
\text { ntos } \\
\text { et al. } \\
{[21]}\end{array}$ & [21] & \begin{tabular}{|r} 
Delcro \\
ix et \\
al. \\
{$[23]$}
\end{tabular} & $\begin{array}{r}\text { Lugez et al. } \\
{[6]}\end{array}$ & Present & $\begin{array}{r}\text { Barrient } \\
\text { os et al. } \\
{[21]}\end{array}$ & Present & $\begin{array}{l}\text { Barriento } \\
\text { s et al. } \\
{[21]}\end{array}$ & $\begin{array}{l}\text { Barriento } \\
\text { s et al. } \\
{[21]}\end{array}$ & $\begin{array}{l}\text { Delcroi } \\
\mathrm{x} \text { et al. } \\
{[23]}\end{array}$ & $\begin{array}{l}\text { Lugez et } \\
\text { al. [6] }\end{array}$ \\
\hline 366 & 333 & 349 & 332 & - & 1.65 & 161.9 & $\mathrm{t}(\mathrm{OH})$ & $\mathrm{t}(\mathrm{COH})$ & $\mathrm{t}(\mathrm{COH})$ & - & - \\
\hline 371 & 368 & 366 & 361 & - & 3.44 & 57.5 & $\mathrm{t}(\mathrm{OH})$ & $\mathrm{t}(\mathrm{COH})$ & $\mathrm{t}(\mathrm{COH})$ & - & - \\
\hline 539 & 538 & 545 & 538 & $545-548$ & 1.36 & 62.7 & $\delta(\mathrm{OCO})$ & $\delta(\mathrm{OCO})$ & $\delta(\mathrm{OCO})$ & - & $\mathrm{t}(\mathrm{CO})$ \\
\hline 973 & 1010 & 985 & 986 & - & 0.38 & 20.5 & $\begin{array}{l}\rho\left(\mathrm{CH}_{2}\right)+ \\
\delta(\mathrm{OH})\end{array}$ & $\rho\left(\mathrm{CH}_{2}\right)$ & $\rho\left(\mathrm{CH}_{2}\right)$ & - & - \\
\hline 995 & 1019 & 1024 & 1025 & - & 1.98 & 95.2 & $v_{\mathrm{s}}(\mathrm{OCO})$ & $v(\mathrm{OCO})$ & $v(\mathrm{OCO})$ & $v_{\mathrm{s}}(\mathrm{CO})$ & - \\
\hline 1003 & 1048 & 1070 & 1026 & $1055-1057$ & 6.55 & 243.7 & $v_{a}(\mathrm{OCO})$ & $v(\mathrm{OCO})$ & $v(\mathrm{OCO})$ & $v_{a}(C O)$ & $v(\mathrm{CO})$ \\
\hline 1165 & 1188 & 1178 & 1177 & - & 0.04 & 1.6 & $\begin{array}{l}\tau\left(\mathrm{CH}_{2}\right) \\
+\delta(\mathrm{OH})\end{array}$ & $\delta(\mathrm{COH})$ & $\delta(\mathrm{COH})$ & - & - \\
\hline 1323 & 1329 & 1341 & 1339 & 1335 & 0.55 & 28.7 & $\begin{array}{l}\omega\left(\mathrm{CH}_{2}\right)+ \\
\delta(\mathrm{OH})\end{array}$ & $\delta(\mathrm{COH})$ & $\delta(\mathrm{COH})$ & - & $\omega\left(\mathrm{CH}_{2}\right)$ \\
\hline 1345 & 1350 & 1360 & 1355 & $1354-1359$ & 0.07 & 3.4 & $\begin{array}{l}\tau\left(\mathrm{CH}_{2}\right) \\
+\delta(\mathrm{OH})\end{array}$ & $\tau\left(\mathrm{CH}_{2}\right)$ & $\tau\left(\mathrm{CH}_{2}\right)$ & - & $\begin{array}{l}\delta(\mathrm{COH}) \text { in- } \\
\text { plane }\end{array}$ \\
\hline 1387 & 1374 & 1413 & 1407 & $1424-1426$ & 1.08 & 60.7 & $\begin{array}{l}\omega\left(\mathrm{CH}_{2}\right)+ \\
\delta(\mathrm{OH})\end{array}$ & $\sigma\left(\mathrm{CH}_{2}\right)$ & $\omega\left(\mathrm{CH}_{2}\right)$ & - & $\begin{array}{l}\delta(\mathrm{COH}) \text { in- } \\
\text { plane }\end{array}$ \\
\hline 1463 & 1441 & 1498 & 1472 & - & 0.00 & 0.3 & $\sigma\left(\mathrm{CH}_{2}\right)$ & $\omega\left(\mathrm{CH}_{2}\right)$ & $\sigma\left(\mathrm{CH}_{2}\right)$ & - & - \\
\hline 2951 & 2807 & 2956 & 2959 & - & 1.34 & 49.9 & $v_{\mathrm{s}}\left(\mathrm{CH}_{2}\right)$ & $v\left(\mathrm{CH}_{2}\right)$ & $v\left(\mathrm{CH}_{2}\right)$ & $v_{\mathrm{s}}\left(\mathrm{CH}_{2}\right)$ & - \\
\hline
\end{tabular}




\begin{tabular}{|r|r|r|r|r|r|r|l|l|l|l|l|}
2999 & 3020 & 3007 & 3016 & 2978 & 0.87 & 33.5 & $v_{\mathrm{a}}\left(\mathrm{CH}_{2}\right)$ & $v\left(\mathrm{CH}_{2}\right)$ & $v\left(\mathrm{CH}_{2}\right)$ & $v_{\mathrm{a}}\left(\mathrm{CH}_{2}\right)$ & $v_{\mathrm{a}}\left(\mathrm{CH}_{2}\right)$ \\
\hline 3683 & 3648 & 3710 & 3753 & 3564 & 0.63 & 47.5 & $v(\mathrm{OH})$ & $v(\mathrm{OH})$ & $v(\mathrm{OH})$ & $v_{\mathrm{a}}(\mathrm{OH})$ & $v(\mathrm{OH})$ \\
\hline 3684 & 3648 & 3711 & 3755 & $3638-3639$ & 0.58 & 27.5 & $v(\mathrm{OH})$ & $v(\mathrm{OH})$ & $v(\mathrm{OH})$ & $v_{\mathrm{s}}(\mathrm{OH})$ & $v(\mathrm{OH})$ \\
\hline
\end{tabular}

Table 3. Vibrational frequencies $\left[\mathrm{cm}^{-1}\right]$, infrared intensities and assignments ${ }^{\S}$ of methoxylated methylene glycol (MMG) conformer A.

\begin{tabular}{|c|c|c|c|c|c|c|c|c|c|c|}
\hline \multicolumn{5}{|c|}{ Vibrational frequencies } & \multicolumn{3}{|c|}{ IR Intensity } & \multicolumn{3}{|l|}{ Assignment $\S$} \\
\hline DFT PBE & $\begin{array}{r}\text { DFT } \\
\text { B3LYP }\end{array}$ & $\begin{array}{r}\text { Expt in } \\
\text { argon } \\
\text { matrix }\end{array}$ & $\begin{array}{r}\text { Expt } \\
\text { gas }\end{array}$ & $\begin{array}{r}\text { Expt } \\
\text { in liquid } \\
\text { methanol }\end{array}$ & DFT PBE & $\begin{array}{r}\text { DFT } \\
\text { B3LYP }\end{array}$ & $\begin{array}{l}\text { Expt in } \\
\text { argon } \\
\text { matrix }\end{array}$ & DFT PBE & DFT B3LYP & Expt argon matrix \\
\hline Present & [7] & [7] & {$[17]$} & {$[18]$} & Present & [7] & [7] & Present & {$[7]$} & [7] \\
\hline 137 & 144 & - & - & - & 0.06 & 2 & - & $\mathrm{t}\left(\mathrm{CH}_{3}\right)$ & $\mathrm{t}(\mathrm{CH})$ & - \\
\hline 180 & 191 & - & - & - & 0.17 & 4 & - & $\mathrm{t}\left(\mathrm{CH}_{3}\right)$ & $\mathrm{t}\left(\mathrm{CH}_{3}\right)$ & - \\
\hline 351 & 358 & - & - & - & 1.48 & 44 & - & $\mathrm{t}(\mathrm{OH})+\delta(\mathrm{COC})$ & $\mathrm{t}(\mathrm{OH})$ & - \\
\hline 383 & 394 & - & - & - & 1.48 & 36 & - & $\mathrm{t}(\mathrm{OH})$ & - & - \\
\hline 564 & 583 & 576 & - & - & 0.58 & 18 & 14 & $\begin{array}{l}\sigma(\mathrm{OCO})+\sigma(\mathrm{COC})+ \\
\mathrm{t}(\mathrm{OH})\end{array}$ & $v(\mathrm{COC})+\delta(\mathrm{OH})$ & $v(\mathrm{COC})+\delta(\mathrm{OH})$ \\
\hline 904 & 925 & 936 & 930 & 925 & 0.93 & 23 & 20 & $v_{\mathrm{s}}(\mathrm{COC})$ & $v_{\mathrm{s}}(\mathrm{COC})$ & $v_{s}(\mathrm{COC})$ \\
\hline 981 & 1024 & 1020 & 1020 & - & 4.57 & 100 & 94 & $v(\mathrm{CO})+\delta(\mathrm{OH})$ & $v(\mathrm{COH})$ & $v(\mathrm{COH})$ \\
\hline 1004 & 1037 & 1044 & $\begin{array}{r}1046 \\
1052 b \\
\end{array}$ & 1067 & 1.86 & 56 & - & $\begin{array}{l}\rho\left(\mathrm{CH}_{2}\right)+\delta(\mathrm{OH})+ \\
v_{\mathrm{a}}(\mathrm{OCO})+v_{\mathrm{a}}(\mathrm{COC}) \\
\end{array}$ & $v(\mathrm{COC})+\sigma\left(\mathrm{CH}_{2}\right)$ & $v(\mathrm{COC})+\sigma\left(\mathrm{CH}_{2}\right)$ \\
\hline 1097 & 1134 & 1125 & 1129 & - & 2.79 & 81 & 100 & $\begin{array}{l}v_{\mathrm{a}}(\mathrm{COC})+\rho\left(\mathrm{CH}_{2}\right)+ \\
\delta(\mathrm{OH})\end{array}$ & $v(\mathrm{COC})+\left(\mathrm{CH}_{2}\right)^{\#}$ & $v(\mathrm{COC})+\left(\mathrm{CH}_{2}\right)^{\#}$ \\
\hline 1130 & 1171 & 1150 & - & 1123 & 0.12 & 2 & 2 & $\rho\left(\mathrm{CH}_{3}\right)$ & $\left(\mathrm{CH}_{2}\right)^{\#}$ & - \\
\hline 1153 & 1200 & 1187 & 1189 & 1200 & 0.36 & 16 & 34 & $\rho\left(\mathrm{CH}_{3}\right)+\tau\left(\mathrm{CH}_{2}\right)+\delta(\mathrm{OH})$ & $\left(\mathrm{CH}_{3}\right)^{\#}+\left(\mathrm{CH}_{2}\right)^{\#}$ & $\left(\mathrm{CH}_{3}\right)^{\#}+\left(\mathrm{CH}_{2}\right)^{\#}$ \\
\hline
\end{tabular}




\begin{tabular}{|c|c|c|c|c|c|c|c|c|c|c|}
\hline 1252 & 1299 & 1286 & & 1303 & 0.35 & 9 & 9 & $\tau\left(\mathrm{CH}_{2}\right)+\delta(\mathrm{OH})$ & $\left(\mathrm{CH}_{3}\right)^{\#}+\left(\mathrm{CH}_{2}\right)^{\#}$ & $\left(\mathrm{CH}_{3}\right)^{\#}+\left(\mathrm{CH}_{2}\right)^{\#}$ \\
\hline 1334 & 1379 & 1355 & 1350 & - & 0.22 & 5 & 10 & $\tau\left(\mathrm{CH}_{2}\right)+\delta(\mathrm{OH})$ & $\left(\mathrm{CH}_{3}\right)^{\#}+\delta\left(\mathrm{CH}_{2}\right)$ & $\delta\left(\mathrm{CH}_{2}\right)$ \\
\hline 1374 & 1433 & 1406 & 1410 & - & 0.42 & 13 & 3 & $\omega\left(\mathrm{CH}_{2}\right)+\delta(\mathrm{OH})$ & $\omega\left(\mathrm{CH}_{3}\right)$ & $\omega\left(\mathrm{CH}_{2}\right)$ \\
\hline 1414 & 1473 & 1444 & - & - & 0.17 & 6 & 4 & $\mathrm{CH}_{3}$ umbrella & $\delta\left(\mathrm{CH}_{3}\right)$ & $\delta\left(\mathrm{CH}_{3}\right)$ \\
\hline 1428 & 1486 & 1452 & 1450 & - & 0.14 & 2 & 7 & $\mathrm{~d}-\sigma\left(\mathrm{CH}_{3}\right)$ & $\delta\left(\mathrm{CH}_{3}\right)$ & - \\
\hline 1446 & 1506 & 1470 & - & - & 0.02 & 2 & 6 & $\sigma\left(\mathrm{CH}_{2}\right)+\mathrm{d}-\sigma\left(\mathrm{CH}_{3}\right)$ & $\delta\left(\mathrm{CH}_{3}\right)$ & - \\
\hline 1454 & 1511 & - & - & - & 0.23 & 3 & - & $\mathrm{d}-\sigma\left(\mathrm{CH}_{3}\right)+\sigma\left(\mathrm{CH}_{2}\right)$ & $\delta\left(\mathrm{CH}_{3}\right)$ & - \\
\hline 2921 & 2994 & 2878 & - & - & 1.33 & 31 & 13 & $v_{\mathrm{s}}\left(\mathrm{CH}_{3}\right)$ & $v_{\mathrm{a}}\left(\mathrm{CH}_{2}\right)$ & $v_{a}\left(\mathrm{CH}_{2}\right)$ \\
\hline 2932 & 3017 & 2929 & - & - & 1.57 & 39 & 15 & $v_{\mathrm{s}}\left(\mathrm{CH}_{2}\right)$ & $v_{\mathrm{a}}\left(\mathrm{CH}_{2}\right)$ & $v_{\mathrm{a}}\left(\mathrm{CH}_{2}\right)$ \\
\hline 2991 & 3064 & 2964 & - & - & 0.79 & 20 & 13 & $v_{\mathrm{a}}\left(\mathrm{CH}_{2}\right)$ & $v(\mathrm{CH})+v_{\mathrm{s}}\left(\mathrm{CH}_{2}\right)$ & $v(\mathrm{CH})+v_{\mathrm{s}}\left(\mathrm{CH}_{2}\right)$ \\
\hline 2995 & 3073 & - & - & - & 0.91 & 25 & - & $v_{a}\left(\mathrm{CH}_{3}\right)$ & $v(\mathrm{CH})+v_{\mathrm{s}}\left(\mathrm{CH}_{2}\right)$ & $v(\mathrm{CH})+v_{\mathrm{s}}\left(\mathrm{CH}_{2}\right)$ \\
\hline 3057 & 3125 & - & - & - & 0.41 & 12 & - & $v_{a}\left(\mathrm{CH}_{3}\right)$ & $v(\mathrm{CH})+v_{\mathrm{s}}\left(\mathrm{CH}_{2}\right)$ & - \\
\hline 3682 & 3815 & 3631 & 3695 & - & 0.67 & 20 & 18 & $v(\mathrm{OH})$ & $v(\mathrm{OH})$ & $v(\mathrm{OH})$ \\
\hline
\end{tabular}

$\S$ Vibrational mode labels: torsion $(\mathrm{t})$, stretch $(v)$, symmetric stretch $\left(v_{\mathrm{s}}\right)$, antisymmetric stretch $\left(v_{\mathrm{a}}\right)$, bend $(\delta)$, twist $(\tau)$, scissor $(\sigma)$, wag $(\omega), \operatorname{rock}(\rho)$. The $\mathrm{CH}_{3}$ 'umbrella' mode refers to a symmetric in-phase deformation, the $\mathrm{CH}_{3} \mathrm{~d}-\sigma$ mode is a degenerate (or nearly) scissor mode, which is an out-of-phase half-methyl deformation [30].

\# Wrobel labelled these modes as $\omega$ in the paper, but this did not correspond to a wag mode as wag modes were explicitly labelled 'wag'. Wrobel did not define $\mathrm{t}$ and $\delta$ so we assume these correspond to torsion and bending modes.

${ }^{b}$ The two values reported by Johnson and Stanley are likely to be just a single peak.

Table 4. Calculated vibrational frequencies, IR intensities and mode assignments ${ }^{\S}$ for the lowest energy conformer, A, and second lowest energy conformer B, of diglycol (DG).

\begin{tabular}{|l|l|l|l|l|l|l|l|l|}
\hline \multicolumn{7}{|c|}{ Vibrational frequencies } & \multicolumn{3}{|c|}{ IR intensity } & Assignment $\S$ \\
\hline DFT PBE & DFT PBE & DFT PBE & DFT PBE & DFT PBE & DFT PBE & DFT PBE & DFT PBE & AIMD \\
\hline
\end{tabular}




\begin{tabular}{|c|c|c|c|c|c|c|c|c|}
\hline & & anharmonic & $\begin{array}{r}\text { harmonic } \\
\text { scaled }\end{array}$ & & & & & \\
\hline Present A & Present B & [23] & {$[23]$} & Present A & Present B & Present A & Present B & {$[23]$} \\
\hline 121 & 25 & 72 & 75 & 0.14 & 0.12 & $\mathrm{t}$ & $\mathrm{t}$ & $\mathrm{t}$ \\
\hline 145 & 161 & 166 & 165 & 0.05 & 0.36 & $\mathrm{t}$ & $\mathrm{t}$ & $\mathrm{t}$ \\
\hline 308 & 285 & 302 & 305 & 3.49 & 0.37 & $\mathrm{t}(\mathrm{OH})$ & $\mathrm{t}$ & $\sigma(\mathrm{COC})$ \\
\hline 393 & 299 & 356 & 351 & 0.17 & 2.18 & $\sigma(\mathrm{COC})$ & $\mathrm{t}(\mathrm{OH})$ & $\omega(\mathrm{OH})$ \\
\hline 464 & 370 & - & 372 & 1.35 & 2.42 & $\mathrm{t}(\mathrm{OH})+\sigma(\mathrm{OCO})$ & $\mathrm{t}(\mathrm{OH})$ & - \\
\hline 508 & 550 & 562 & 583 & 1.87 & 0.18 & $\mathrm{t}(\mathrm{OH})$ & $\begin{array}{l}\sigma(\mathrm{COC})+\sigma(\mathrm{OCO})+ \\
\mathrm{t}(\mathrm{OH})\end{array}$ & sym $\sigma(\mathrm{OCO})$ \\
\hline 617 & 566 & 582 & 594 & 0.40 & 0.70 & $\begin{array}{l}\sigma(\mathrm{COC})+\sigma(\mathrm{OCO})+ \\
\mathrm{t}(\mathrm{OH})\end{array}$ & $\begin{array}{l}\sigma(\mathrm{COC})+\sigma(\mathrm{OCO})+ \\
\mathrm{t}(\mathrm{OH})\end{array}$ & asym $\sigma(\mathrm{OCO})$ \\
\hline 886 & 896 & 916 & 936 & 1.45 & 0.79 & $v_{\mathrm{s}}(\mathrm{COC})+\mathrm{v}_{\mathrm{a}}(\mathrm{OCO})$ & $v_{\mathrm{s}}(\mathrm{COC})$ & $v_{\mathrm{s}}(\mathrm{CO})$ \\
\hline 949 & 935 & 1011 & 1002 & 4.19 & 8.86 & $\mathrm{v}_{\mathrm{a}}(\mathrm{COC})+\mathrm{v}_{\mathrm{a}}(\mathrm{OCO})$ & $\begin{array}{l}\mathrm{v}_{\mathrm{a}}(\mathrm{OCO})+\mathrm{v}_{\mathrm{a}}(\mathrm{COC}) \\
+\delta(\mathrm{OH})\end{array}$ & $v_{a}(C O)$ \\
\hline 985 & 981 & 1012 & 1030 & 2.85 & 3.88 & $\rho\left(\mathrm{CH}_{2}\right)+\delta(\mathrm{OH})$ & $\begin{array}{l}\rho\left(\mathrm{CH}_{2}\right)+\mathrm{v}\left(\mathrm{CO}_{\mathrm{H}}\right)+ \\
\delta(\mathrm{OH})\end{array}$ & $v_{a}(C O)$ \\
\hline 1033 & 1024 & 1040 & 1057 & 4.40 & 1.14 & $v\left(\mathrm{CO}_{\mathrm{H}}\right)+\delta(\mathrm{OH})$ & $v\left(\mathrm{CO}_{\mathrm{H}}\right)$ & $v_{\mathrm{s}}(\mathrm{CO})+\delta\left(\mathrm{CH}_{2}\right)$ \\
\hline 1050 & 1030 & 1127 & 1103 & 1.06 & 1.53 & $\rho\left(\mathrm{CH}_{2}\right)+\delta(\mathrm{OH})$ & $\rho\left(\mathrm{CH}_{2}\right)+\delta(\mathrm{OH})$ & $v_{a}(C O)$ \\
\hline 1078 & 1076 & 1140 & 1128 & 2.35 & 1.96 & $\begin{array}{l}\mathrm{v}_{\mathrm{a}}(\mathrm{COC})+\rho\left(\mathrm{CH}_{2}\right)+ \\
\delta(\mathrm{OH})\end{array}$ & $\begin{array}{l}\mathrm{v}_{\mathrm{a}}(\mathrm{COC})+\rho\left(\mathrm{CH}_{2}\right)+ \\
\delta(\mathrm{OH})\end{array}$ & $\delta\left(\mathrm{CH}_{2}\right)+v_{\mathrm{s}}(\mathrm{CO})$ \\
\hline 1211 & 1211 & 1245 & 1262 & 0.76 & 0.50 & $\tau\left(\mathrm{CH}_{2}\right)+\delta(\mathrm{OH})$ & $\tau\left(\mathrm{CH}_{2}\right)+\delta(\mathrm{OH})$ & $\delta\left(\mathrm{CH}_{2}\right)+\delta(\mathrm{OH})$ \\
\hline 1271 & 1262 & 1287 & 1315 & 0.41 & 0.37 & $\tau\left(\mathrm{CH}_{2}\right)+\delta(\mathrm{OH})$ & $\tau\left(\mathrm{CH}_{2}\right)+\delta(\mathrm{OH})$ & $\delta\left(\mathrm{CH}_{2}\right)+\delta(\mathrm{OH})$ \\
\hline 1331 & 1332 & 1378 & 1381 & 0.20 & 0.20 & $\tau\left(\mathrm{CH}_{2}\right)+\delta(\mathrm{OH})$ & $\tau\left(\mathrm{CH}_{2}\right)+\delta(\mathrm{OH})$ & $\delta(\mathrm{OH})+\delta\left(\mathrm{CH}_{2}\right)$ \\
\hline 1343 & 1336 & 1374 & 1384 & 0.26 & 0.16 & $\omega\left(\mathrm{CH}_{2}\right)+\delta(\mathrm{OH})$ & $\tau\left(\mathrm{CH}_{2}\right)+\delta(\mathrm{OH})$ & $\delta(\mathrm{OH})+\delta\left(\mathrm{CH}_{2}\right)$ \\
\hline 1376 & 1363 & 1401 & 1418 & 0.53 & 0.56 & $\omega\left(\mathrm{CH}_{2}\right)$ & $\omega\left(\mathrm{CH}_{2}\right)+\delta(\mathrm{OH})$ & $\operatorname{sym} \delta\left(\mathrm{CH}_{2}\right)$ \\
\hline 1397 & 1382 & 1428 & 1446 & 0.98 & 0.27 & $\omega\left(\mathrm{CH}_{2}\right)+\delta(\mathrm{OH})$ & $\omega\left(\mathrm{CH}_{2}\right)+\delta(\mathrm{OH})$ & $\delta\left(\mathrm{CH}_{2}\right)$ \\
\hline
\end{tabular}




\begin{tabular}{|r|r|r|r|r|l|l|l|l|}
\hline 1442 & 1449 & 1478 & 1502 & 0.05 & 0.12 & $\sigma\left(\mathrm{CH}_{2}\right)$ & $\sigma\left(\mathrm{CH}_{2}\right)$ & $\sigma\left(\mathrm{CH}_{2}\right)$ \\
\hline 1456 & 1460 & 1481 & 1506 & 0.07 & 0.02 & $\sigma\left(\mathrm{CH}_{2}\right)$ & $\sigma\left(\mathrm{CH}_{2}\right)$ & $\sigma\left(\mathrm{CH}_{2}\right)$ \\
\hline 2883 & 2950 & 2901 & 3037 & 1.57 & 2.10 & $v_{\mathrm{s}}\left(\mathrm{CH}_{2}\right)$ & $v_{\mathrm{s}}\left(\mathrm{CH}_{2}\right)$ & $v_{\mathrm{s}}(\mathrm{CH})$ \\
\hline 2944 & 2956 & 2901 & 3043 & 1.36 & 0.17 & $v_{\mathrm{s}}\left(\mathrm{CH}_{2}\right)$ & $v_{\mathrm{s}}\left(\mathrm{CH}_{2}\right)$ & $v_{\mathrm{s}}(\mathrm{CH})$ \\
\hline 3008 & 3004 & 2948 & 3100 & 0.90 & 0.77 & $v_{\mathrm{a}}\left(\mathrm{CH}_{2}\right)$ & $v_{\mathrm{a}}\left(\mathrm{CH}_{2}\right)$ & $v_{\mathrm{a}}(\mathrm{CH})$ \\
\hline 3051 & 3053 & 2950 & 3102 & 0.59 & 0.45 & $v_{\mathrm{a}}\left(\mathrm{CH}_{2}\right)$ & $v_{\mathrm{a}}\left(\mathrm{CH}_{2}\right)$ & $v_{\mathrm{a}}(\mathrm{CH})$ \\
\hline 3646 & 3686 & 3715 & 3844 & 1.68 & 0.61 & $v(\mathrm{OH})$ & $v(\mathrm{OH})$ & $v_{\mathrm{a}}(\mathrm{OH})$ \\
\hline 3687 & 3722 & 3716 & 3846 & 0.66 & 0.90 & $v(\mathrm{OH})$ & $v(\mathrm{OH})$ & $v_{\mathrm{s}}(\mathrm{OH})$ \\
\hline
\end{tabular}

$\S$ Vibrational modes: torsion $(\mathrm{t})$, stretch $(v)$, symmetric stretch $\left(v_{\mathrm{s}}\right)$, antisymmetric stretch $\left(v_{\mathrm{a}}\right)$, bend $(\delta)$, twist $(\tau)$, scissor $(\sigma)$, wag $(\omega)$, $\operatorname{rock}(\rho)$.

Table 5. Assignments of vibrational frequencies for species in formaldehyde-water-methanol solutions.

\begin{tabular}{|c|c|c|c|c|c|c|c|c|c|c|}
\hline \multirow[b]{2}{*}{$\begin{array}{l}\text { Peak } \\
\text { label }\end{array}$} & \multicolumn{10}{|c|}{ Wavenumbers and Assignments $\S$} \\
\hline & $\begin{array}{l}\text { IR/ } \\
\text { Raman }\end{array}$ & DFT PBE & $\begin{array}{l}\text { Raman } \\
\text { (aqueous } \\
\text { formaldhyde) }\end{array}$ & $\begin{array}{l}\text { Raman* } \\
\text { (aqueous } \\
\text { formaldehyde } \\
\text { ) }\end{array}$ & $\begin{array}{l}\text { Raman (stock } \\
\text { solution w/ } \\
\text { methanol) }\end{array}$ & $\begin{array}{l}\text { IR (aqueous } \\
\text { formaldehyde } \\
\text { ) }\end{array}$ & IR (MG) & $\begin{array}{l}\text { IR (MMG } \\
\text { in gas) }\end{array}$ & $\begin{array}{l}\text { IR } \\
(\mathrm{MMG} \text { in } \\
\mathrm{MeOH})\end{array}$ & $\begin{array}{l}\text { IR (MMG } \\
\text { a/b } \\
\text { conformers } \\
\text { in argon) }\end{array}$ \\
\hline $\mathbf{A}$ & 910/905 & $\begin{array}{l}\text { DG 886 } v_{s}(\text { COC })+ \\
v_{a}(\text { OCO })\end{array}$ & $\begin{array}{l}\mathbf{9 2 7} \\
v_{\mathrm{s}}(\mathrm{OCO} / \mathrm{COC} \\
) \text { in oligomers }\end{array}$ & $\begin{array}{l}\mathbf{9 1 0} \\
\mathrm{v}_{\mathrm{s}}(\mathrm{OCO}) \text { in } \\
\text { oligomer } \\
\text { chains }\end{array}$ & $\begin{array}{l}907 \\
\mathrm{v}_{\mathrm{s}}(\mathrm{OCO}) \text { in } \\
\mathrm{MG}\end{array}$ & --- & --- & --- & --- & --- \\
\hline
\end{tabular}




\begin{tabular}{|c|c|c|c|c|c|c|c|c|c|c|}
\hline & & & & & & & & & & $v_{s}(\mathrm{COC})$ \\
\hline $\mathrm{C}$ & $960 / 950$ & $\begin{array}{l}\text { DG } 949 v_{a}(\text { OCO })+ \\
v_{a}(\text { COC })\end{array}$ & --- & $\begin{array}{l}933 \\
\mathrm{v}_{\mathrm{s}}(\mathrm{OCO}) \text { in } \\
\text { oligomer } \\
\text { endgoups }\end{array}$ & --- & --- & --- & --- & --- & --- \\
\hline D & 990/995 & $\begin{array}{l}\text { MG } 973 \rho\left(\mathrm{CH}_{2}\right)+ \\
\delta(\mathrm{OH}) \\
\text { DG } 985 \rho\left(\mathrm{CH}_{2}\right)+ \\
\delta(\mathrm{OH})\end{array}$ & --- & --- & --- & $\begin{array}{l}992 \\
v(\mathrm{COC}) \text { in } \\
\text { oligomers }\end{array}$ & --- & --- & --- & --- \\
\hline $\mathbf{E}$ & $\begin{array}{l}1025 / \\
1025\end{array}$ & $\begin{array}{l}\text { MeOH } 1008 v(\mathrm{CO}) \\
+\delta(\mathrm{OH}) \\
\text { MG } 995 \mathrm{v}_{\mathrm{s}}(\mathrm{OCO}) \\
\text { MMG } 981 v(\mathrm{CO})+ \\
\delta(\mathrm{OH}) \\
\text { DG } 1033 v\left(\mathrm{CO}_{\mathrm{H}}\right)+ \\
\delta(\mathrm{OH})\end{array}$ & --- & $\begin{array}{l}\mathbf{1 0 4 0} \\
v_{\mathrm{a}}(\mathrm{OCO}) \text { in } \\
\text { oligomer } \\
\text { chains }\end{array}$ & $\begin{array}{l}1034 \\
v(\mathrm{CO}) \text { in } \\
\text { liquid } \mathrm{MeOH}\end{array}$ & $\begin{array}{l}\mathbf{1 0 2 6} \\
v(\mathrm{COC}) \text { in } \\
\text { oligomers }\end{array}$ & --- & 1020 & --- & $\begin{array}{l}\mathbf{1 0 2 0} / \mathbf{1 0 1 9} \\
v(\mathrm{COH})\end{array}$ \\
\hline $\mathbf{F}$ & $\begin{array}{l}1060 / \\
1055\end{array}$ & $\begin{array}{l}\text { MG } 1003 v_{a}(\mathrm{OCO}) \\
\text { MMG } 1004 \rho\left(\mathrm{CH}_{2}\right) \\
+\delta(\mathrm{OH})+ \\
v_{\mathrm{a}}(\mathrm{OCO})+ \\
v_{\mathrm{a}}(\mathrm{COC}) \\
\text { DG } 1050 \rho\left(\mathrm{CH}_{2}\right)+ \\
\delta(\mathrm{OH})\end{array}$ & $\begin{array}{l}1063 \\
v_{a}(\mathrm{OCO})\end{array}$ & $\begin{array}{l}\mathbf{1 0 5 9} \\
v_{\mathrm{a}}(\mathrm{OCO}) \text { in } \\
\text { oligomer } \\
\text { endgoups }\end{array}$ & $\begin{array}{l}\mathbf{1 0 5 5} \\
v_{\mathrm{a}}(\mathrm{OCO}) \text { in } \\
\mathrm{MG}\end{array}$ & $\begin{array}{l}\mathbf{1 0 5 0} \\
v(\mathrm{OCO}) \text { in } \\
\mathrm{MG} \\
(\mathbf{1 0 7 2} \\
\mathrm{v}(\mathrm{OCO}) \text { in } \\
\mathrm{DG})\end{array}$ & $\begin{array}{l}1055- \\
1057 \\
v(\mathrm{CO})\end{array}$ & $\begin{array}{l}1046 \& \\
1052 b\end{array}$ & 1067 & $\begin{array}{l}\mathbf{1 0 4 4 / 1 0 6 4} \\
v(\mathrm{COC})+ \\
\sigma\left(\mathrm{CH}_{2}\right)\end{array}$ \\
\hline $\mathbf{G}$ & $1110 /$ & $\begin{array}{l}\text { МeOH } 1052 \\
\mathrm{v}(\mathrm{CO})+\delta(\mathrm{OH})+\end{array}$ & & 1111 & $\begin{array}{l}1109 \rho\left(\mathrm{CH}_{3}\right) \\
\text { in liquid }\end{array}$ & 1100 & --- & 1129 & --- & $1125 / 1119$ \\
\hline
\end{tabular}




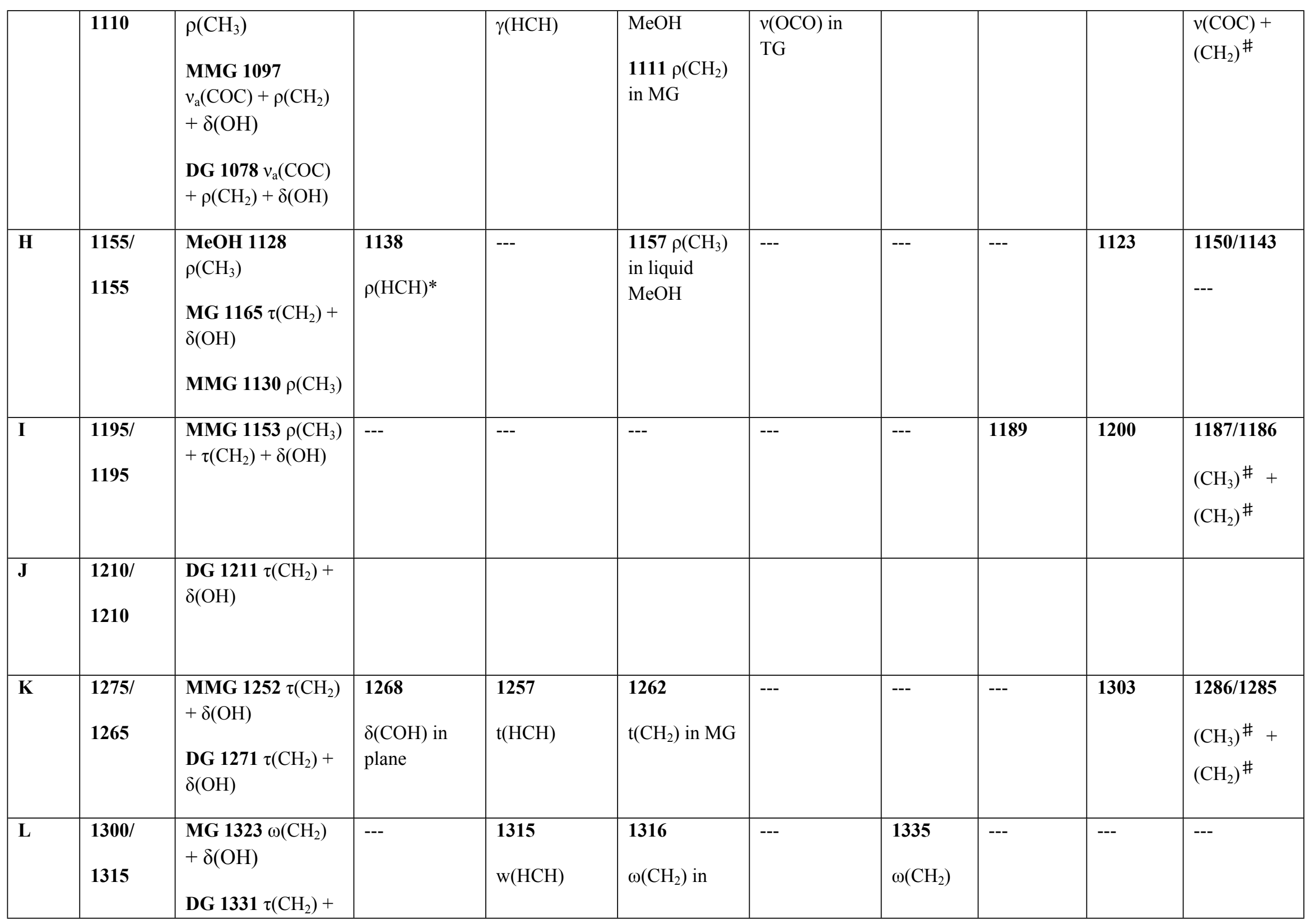




\begin{tabular}{|c|c|c|c|c|c|c|c|c|c|c|}
\hline & & $\delta(\mathrm{OH})$ & & & $\mathrm{MG}$ & & & & & \\
\hline $\mathbf{M}$ & $\begin{array}{l}1330 / \\
1330\end{array}$ & $\begin{array}{l}\text { MG } 1345 \tau\left(\mathrm{CH}_{2}\right)+ \\
\delta(\mathrm{OH}) \\
\text { MMG } 1334 \tau\left(\mathrm{CH}_{2}\right) \\
+\delta(\mathrm{OH}) \\
\text { DG } 1343 \omega\left(\mathrm{CH}_{2}\right)+ \\
\delta(\mathrm{OH})\end{array}$ & $\begin{array}{l}1333 \\
\tau(\mathrm{HCH}) \text { in } \\
\text { oligomers }\end{array}$ & --- & --- & --- & $\begin{array}{l}\text { 1354- } \\
1359 \\
\delta(\mathrm{COH}) \\
\text { in plane }\end{array}$ & 1350 & --- & $\begin{array}{l}\mathbf{1 3 5 5 / 1 3 5 6} \\
\delta\left(\mathrm{CH}_{2}\right)\end{array}$ \\
\hline $\mathbf{N}$ & $\begin{array}{l}1420 / \\
1410\end{array}$ & $\begin{array}{l}\text { MeOH } 1328 \\
\delta(\mathrm{OH})+ \\
\rho\left(\mathrm{CH}_{3}\right) \\
\text { MG } 1387 \omega\left(\mathrm{CH}_{2}\right)+ \\
\delta(\mathrm{OH}) \\
\text { MMG } 1374 \\
\omega\left(\mathrm{CH}_{2}\right)+\delta(\mathrm{OH}) \\
\text { DG } 1376 \omega\left(\mathrm{CH}_{2}\right)\end{array}$ & $\begin{array}{l}1429 \\
\omega(\mathrm{HCH})\end{array}$ & $\begin{array}{l}\mathbf{1 4 0 8} \\
\delta(\mathrm{COH}) \text { in } \\
\text { plane }\end{array}$ & $\begin{array}{l}1412 \\
\delta(\mathrm{COH}) \text { in } \\
\text { plane in } \mathrm{MG}\end{array}$ & --- & $\begin{array}{l}1424- \\
1426 \\
\delta(\mathrm{COH}) \\
\text { in plane }\end{array}$ & 1410 & --- & $\begin{array}{l}\mathbf{1 4 0 6 / 1 4 1 4} \\
\omega\left(\mathrm{CH}_{2}\right)\end{array}$ \\
\hline O & $\begin{array}{l}1450 / \\
1450\end{array}$ & $\begin{array}{l}\text { MeOH } 1422 \mathrm{CH}_{3} \\
\text { umbrella } \\
\text { MMG } 1414 \mathrm{CH}_{3} \\
\text { umbrella } \\
\text { DG } 1397 \omega\left(\mathrm{CH}_{2}\right)+ \\
\delta(\mathrm{OH})\end{array}$ & --- & $\begin{array}{l}\mathbf{1 4 4 0} \\
\delta(\mathrm{COH}) \text { in } \\
\text { plane }\end{array}$ & $\begin{array}{l}\mathbf{1 4 5 0} \mathrm{CH}_{3} \\
\text { sym } \\
\text { deformation } \\
\text { in liquid } \\
\mathrm{MeOH} \\
\mathbf{1 4 5 3} \delta(\mathrm{COH}) \\
\text { in plane in } \\
\mathrm{MG}\end{array}$ & --- & --- & --- & --- & $\begin{array}{l}\mathbf{1 4 4 4 / 1 4 4 4} \\
\delta\left(\mathrm{CH}_{3}\right)\end{array}$ \\
\hline $\mathbf{P}$ & $\begin{array}{l}1470 / \\
1460\end{array}$ & $\begin{array}{l}\text { МeOH } 1441 \text { d- } \\
\sigma\left(\mathrm{CH}_{3}\right) \\
\text { MMG } 1428 \text { d- }\end{array}$ & --- & --- & $\begin{array}{l}1465 \mathrm{CH}_{3} \\
\text { deg. } \\
\text { deformation } \\
\text { in liquid }\end{array}$ & --- & --- & 1450 & --- & $\begin{array}{l}\mathbf{1 4 5 2 / 1 4 5 2} \\
\delta\left(\mathrm{CH}_{3}\right)\end{array}$ \\
\hline
\end{tabular}




\begin{tabular}{|c|c|c|c|c|c|c|c|c|c|c|}
\hline & & $\begin{array}{l}\sigma\left(\mathrm{CH}_{3}\right) \\
\text { DG } 1442 \sigma\left(\mathrm{CH}_{2}\right)\end{array}$ & & & $\mathrm{MeOH}$ & & & & & \\
\hline $\mathbf{Q}$ & $\begin{array}{l}1490 / \\
1480\end{array}$ & $\begin{array}{l}\text { MeOH } 1455 \text { d- } \\
\sigma\left(\mathrm{CH}_{3}\right) \\
\text { MG } 1463 \sigma\left(\mathrm{CH}_{2}\right) \\
\text { MMG } 1446 \sigma\left(\mathrm{CH}_{2}\right) \\
+\mathrm{d}-\sigma\left(\mathrm{CH}_{3}\right) \\
\text { DG } 1456 \sigma\left(\mathrm{CH}_{2}\right)\end{array}$ & $\begin{array}{l}1495 \\
\sigma(\mathrm{HCH}) * \text { in } \\
\text { oligomers }\end{array}$ & $\begin{array}{l}1492 \\
\delta(\mathrm{HCH})\end{array}$ & $\begin{array}{l}1488 \\
\sigma\left(\mathrm{CH}_{2}\right) \text { in } \\
\mathrm{MG}\end{array}$ & --- & --- & --- & --- & $\begin{array}{l}\mathbf{1 4 7 0 / 1 4 7 0} \\
\delta\left(\mathrm{CH}_{3}\right)\end{array}$ \\
\hline $\mathbf{R}$ & $\begin{array}{l}1500 / \\
1500\end{array}$ & $\begin{array}{l}\text { MMG } 1454 \text { d- } \\
\sigma\left(\mathrm{CH}_{3}\right)+\sigma\left(\mathrm{CH}_{2}\right)\end{array}$ & --- & --- & --- & --- & --- & --- & --- & --- \\
\hline
\end{tabular}

$\S$ Vibrational modes: torsion $(\mathrm{t})$, stretch $(v)$, symmetric stretch $\left(v_{\mathrm{s}}\right)$, antisymmetric stretch $\left(v_{\mathrm{a}}\right)$, bend $(\delta)$, twist $(\tau)$, scissor $(\sigma)$, wag $(\omega)$, $\operatorname{rock}(\rho)$. The $\mathrm{CH}_{3}$ 'umbrella' mode refers to a symmetric in-phase deformation, the $\mathrm{CH}_{3} \mathrm{~d}-\sigma$ mode is a degenerate (or nearly) scissor mode, which is an out-of-phase half-methyl deformation [30]. The final column shows experimental IR values by Wrobel et al and the two wavenumbers correspond to two different conformers ( $a$ and $b$ ) of MMG.

*Note that Lebrun et al did not define their symbols for mode assignments so we reported their assignments as shown in their paper. The original paper by Mohlmann uses $\gamma$ to denote rock and $\delta$ to denote scissor.

\# Wrobel labelled these modes as $\omega$ in the paper, but this did not correspond to a wag mode as this was labelled as 'wag'. Wrobel did not define $t$ and $\delta$ and we assume these correspond to torsion and bending modes.

b The two values reported by Johnson and Stanley are likely to be just a single peak, which we have attributed to our peak F. 


\section{References}

[1] H.R. Gerberich, G.C. Seaman, Kirk-Othmer Encyclopedia of Chemical Technology, John Wiley \& Sons, Inc., Hoboken, NJ, USA, 2004.

[2] S.A. Al-Muhtaseb, J.A. Ritter, Preparation and Properties of Resorcinol-Formaldehyde Organic and Carbon Gels, Adv. Mater. 15 (2003) 101-114. doi:10.1002/adma.200390020.

[3] A.M. ElKhatat, S.A. Al-Muhtaseb, Advances in Tailoring Resorcinol-Formaldehyde Organic and Carbon Gels, Adv. Mater. 23 (2011) 2887-2903. doi:10.1002/adma.201100283.

[4] K.Z. Gaca, J.A. Parkinson, L. Lue, J. Sefcik, Equilibrium Speciation in Moderately Concentrated Formaldehyde-Methanol-Water Solutions Investigated Using $13 \mathrm{C}$ and $1 \mathrm{H}$ Nuclear Magnetic Resonance Spectroscopy, Ind. Eng. Chem. Res. (2014). doi:10.1021/ie403252x.

[5] S.J. Taylor, M.D. Haw, J. Sefcik, A.J. Fletcher, Gelation Mechanism of Resorcinol-Formaldehyde Gels Investigated by Dynamic Light Scattering, Langmuir. 30 (2014) 10231-10240. doi:10.1021/la502394u.

[6] C. Lugez, A. Schriver, R. Levant, L. Schriver-Mazzuoli, A matrix-isolation infrared spectroscopic study of the reactions of methane and methanol with ozone, Chem. Phys. 181 (1994) 129-146. doi:10.1016/0301-0104(94)85021-6.

[7] R. Wrobel, W. Sander, E. Kraka, D. Cremer, Reactions of Dimethyl Ether with Atomic Oxygen: A Matrix Isolation and a Quantum Chemical Study, J. Phys. Chem. A. 103 (1999) 3693-3705. doi:10.1021/jp984631f.

[8] B. Chazallon, N. Lebrun, P. Dhamelincourt, C. Toubin, C. Focsa, Micro-Raman Investigations of the Formaldehyde-Ice System, J. Phys. Chem. B. 109 (2005) 432-439. doi:10.1021/jp040244w.

[9] J.-O. Drunsel, M. Renner, H. Hasse, Experimental study and model of reaction kinetics of heterogeneously catalyzed methylal synthesis, Chem. Eng. Res. Des. 90 (2012) 696-703.

[10] D.J.J. Le Botlan, B.G.G. Mechin, G.J.J. Martin, Proton and carbon-13 nuclear magnetic resonance spectrometry of formaldehyde in water, Anal. Chem. 55 (1983) 587-591.

doi:10.1021/ac00254a041.

[11] H. Hasse, G. Maurer, Kinetics of the poly(oxymethylene) glycol formation in aqueous formaldehyde solutions, Ind. Eng. Chem. Res. 30 (1991) 2195-2200. doi:10.1021/ie00057a022.

[12] M. Ott, H.H. Fischer, M. Maiwald, K. Albert, H. Hasse, Kinetics of oligomerization reactions in formaldehyde solutions: NMR experiments up to $373 \mathrm{~K}$ and thermodynamically consistent model, Chem. Eng. Process. Process Intensif. 44 (2005) 653-660. doi:10.1016/j.cep.2003.07.004.

[13] H. Matsuura, M. Yamamoto, H. Murata, Raman spectra and normal vibrations of methylene glycol and its perdeuterated analogue, Spectrochim. Acta Part A Mol. Spectrosc. 36 (1980) 321-327. doi:10.1016/0584-8539(80)80137-1.

[14] G.R. Möhlmann, Raman spectra of aqueous solutions of formaldehyde and its oligomers, J. Raman Spectrosc. 18 (1987) 199-203. doi:10.1002/jrs.1250180310.

[15] N. Lebrun, P. Dhamelincourt, C. Focsa, B. Chazallon, J.L. Destombes, D. Prevost, Raman analysis of formaldehyde aqueous solutions as a function of concentration, J. Raman Spectrosc. 34 (2003) 459-464. doi:10.1002/jrs.1025. 
[16] J. Monni, P. Niemelä, L. Alvila, T.T. Pakkanen, Online monitoring of synthesis and curing of phenol-formaldehyde resol resins by Raman spectroscopy, Polymer (Guildf). 49 (2008) 38653874. doi:10.1016/j.polymer.2008.06.050.

[17] R.A.A. Johnson, A.E.E. Stanley, GC/MS and FT-IR Spectra of Methoxymethanol, Appl. Spectrosc. 45 (1991) 218-222. http://as.osa.org/abstract.cfm?URI=as-45-2-218 (accessed November 24, 2013).

[18] S. Fanetti, M. Ceppatelli, M. Citroni, R. Bini, High-Pressure Photoinduced Reactivity of $\mathrm{CH} 3 \mathrm{OH}$ and CD3OH, J. Phys. Chem. C. 116 (2012) 2108-2115. doi:10.1021/jp205563d.

[19] R.S. Ryabova, G.I. Voloshenko, V.D. Maiorov, G.F. Osipova, Equilibrium Composition of Formaldehyde Oligomers in Aqueous Solutions from IR Data, Russ. J. Appl. Chem. 75 (2002) $22-$ 24. doi:10.1023/A:1015596218762.

[20] I. Poljanšek, M. Krajnc, Characterization of phenol-formaldehyde prepolymer resins by in line FTIR spectroscopy, Acta Chim. Slov. 52 (2005) 238-244.

[21] C. Barrientos, P. Redondo, H. Martínez, A. Largo, Computational Prediction of the Spectroscopic Parameters of Methanediol, an Elusive Molecule for Interstellar Detection, Astrophys. J. 784 (2014) 132. doi:10.1088/0004-637X/784/2/132.

[22] P. Delcroix, M. Pagliai, G. Cardini, D. Bégué, B. Hanoune, Structural and Spectroscopic Properties of Methanediol in Aqueous Solutions from Quantum Chemistry Calculations and Ab Initio Molecular Dynamics Simulations, J. Phys. Chem. A. 119 (2015) 290-298. doi:10.1021/jp510759r.

[23] P. Delcroix, M. Pagliai, G. Cardini, D. Bégué, B. Hanoune, Identification of Di(oxymethylene)glycol in the Raman Spectrum of Formaldehyde Aqueous Solutions by ab Initio Molecular Dynamics Simulations and Quantum Chemistry Calculations, J. Phys. Chem. A. 119 (2015) 9785-9793. doi:10.1021/acs.jpca.5b06293.

[24] K.Z. Gaca, Kinetics and mechanisms of early stages of resorcinol-formaldehyde polymerization, University of Strathclyde, 2012.

[25] P. Giannozzi, S. Baroni, N. Bonini, M. Calandra, R. Car, C. Cavazzoni, D. Ceresoli, G.L. Chiarotti, M. Cococcioni, I. Dabo, A. Dal Corso, S. de Gironcoli, S. Fabris, G. Fratesi, R. Gebauer, U. Gerstmann, C. Gougoussis, A. Kokalj, M. Lazzeri, L. Martin-Samos, N. Marzari, F. Mauri, R. Mazzarello, S. Paolini, A. Pasquarello, L. Paulatto, C. Sbraccia, S. Scandolo, G. Sclauzero, A.P. Seitsonen, A. Smogunov, P. Umari, R.M. Wentzcovitch, QUANTUM ESPRESSO: a modular and open-source software project for quantum simulations of materials, J. Phys. Condens. Matter. 21 (2009) 395502. doi:10.1088/0953-8984/21/39/395502.

[26] J.P. Perdew, K. Burke, M. Ernzerhof, Generalized Gradient Approximation Made Simple, Phys. Rev. Lett. 77 (1996) 3865-3868. doi:10.1103/PhysRevLett.77.3865.

[27] G. Schaftenaar, J.H. Noordik, Molden: a pre- and post-processing program for molecular and electronic structures, J. Comput. Aided. Mol. Des. 14 (2000) 123-134. doi:10.1023/A:1008193805436.

[28] T. Shimanouchi, Tables of Molecular Vibrational Frequencies Consolidate Volume I, in: Natl. Bur. Stand., 1972: pp. 1-178. doi:10.1063/1.555560. 
[29] S. Dixit, W.C.K. Poon, J. Crain, S. Dixit, W.C.K. Poon, Hydration of methanol in aqueous solutions: a Raman spectroscopic study, J. Phys. Condens. Matter. 12 (2000) L323-L328. doi:10.1088/0953-8984/12/21/103.

[30] N. Colthup, L. Daly, S. Wiberley, Introduction to Infrared and Raman Spectroscopy, Academic Press, 1990. http://www.sciencedirect.com/science/book/9780121825546 (accessed August 6, 2017). 